\title{
Effect of Quartz Overgrowth Precipitation on the Multiscale Porosity of Sandstone: A (U)SANS and Imaging Analysis
}

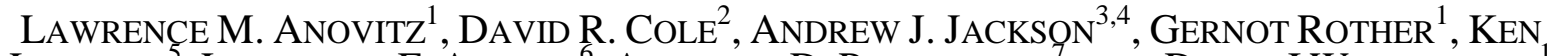 \\ LITTRELL $^{5}$, LAWRENCE F. ALLARD ${ }^{6}$, ANTHONY D. POLLINGTON ${ }^{7}$, AND DAVID J WESOLOWSKI ${ }^{1}$
}

${ }^{1}$ Chemical Sciences Division, MS 6110, Oak Ridge National Laboratory, Oak Ridge, TN USA, anovitzlm@ornl.gov, rotherg@ornl.gov, wesolowskid@ornl.gov

${ }_{3}^{2}$ School of Earth Sciences, Ohio State University, Columbus, OH cole.613@osu

${ }_{4}^{3}$ NIST Center for Neutron Research, Stop 8562, Gaithersburg, MD USA, aji@ nist.gov

${ }^{4}$ University of Delaware, Department of Chemical Engineering, Newark, DE 19716, United States

${ }^{5}$ Neutron Scattering Science Division, MS 6393, Oak Ridge National Laboratory, Oak Ridge, TN USA, littrellkc@ornl.gov

${ }^{6}$ Materials Science and Technology Division, MS 6064, Oak Ridge National Laboratory, Oak Ridge, TN USA, anovitzlm@ornl.gov

${ }^{7}$ Clean Chemistry Team, Nuclear and Radiochemistry (C-NR), Los Alamos National Laboratory, PO Box 1663, MS J514, Los Alamos, NM 87545, pollington@lanl.gov 
We have performed a series of experiments to understand the effects of quartz overgrowths on

59 nanometer to centimeter scale pore structures of sandstones. Blocks from two samples of St.

60 Peter Sandstone with different initial porosities (5.8 and 18.3\%) were reacted from 3 days to 7.5

61 months at 100 and $200^{\circ} \mathrm{C}$ in aqueous solutions supersaturated with respect to quartz by reaction

62 with amorphous silica. Porosity in the resultant samples was analyzed using small and ultrasmall

63 angle neutron scattering and scanning electron microscope/backscattered electron (SEM/BSE) -

64 based image-scale processing techniques.

65 Significant changes were observed in the multiscale pore structures. By three days much of 66 the overgrowth in the low-porosity sample dissolved away. The reason for this is uncertain, but

67 the overgrowths can be clearly distinguished from the original core grains in the BSE images. At

68 longer times the larger pores are observed to fill with plate-like precipitates. As with the

69 unreacted sandstones, porosity is a step function of size. Grain boundaries are typically fractal,

70 but no evidence of mass fractal or fuzzy interface behavior was observed suggesting a structural

71 difference between chemical and clastic sediments. After the initial loss of the overgrowths,

72 image scale porosity $(>\sim 1 \mathrm{~cm})$ decreases with time. Submicron porosity (typically $\sim 25 \%$ of the

73 total) is relatively constant or slightly decreasing in absolute terms, but the percent change is

74 significant. Fractal dimensions decrease at larger scales, and increase at smaller scales with 75 increased precipitation. 


\subsection{Introduction}

78 The microstructure and evolution of porosity in time and space play a critical role in many

79 geologic processes, including the migration and retention of water, gas and hydrocarbons, the

80 evolution of hydrothermal systems, weathering, diagenesis and metamorphism, as well as

81 technological processes such as $\mathrm{CO}_{2}$ sequestration, shale gas and secondary oil recovery. The

82 size, distribution and connectivity of these confined geometries collectively dictate how fluids

83 migrate into and through these micro- and nanoenvironments, wet and react with mineral

84 surfaces. To properly interpret the time-temperature-pressure history of a geological system the

85 physical and chemical "fingerprints" of this evolution in the rock should be interrogated from the

86 nanoscale to the macroscale.

87 In many sandstones formation of pore-filling overgrowths plays a critical role in the 88 modification of porosity at all scales. However, the effect of pore scale and substrate

89 composition on pore filling processes remains unclear. It has been suggested, on the basis of

90 observations of pore-filling in sandstones (Putnis and Mauthe, 2001, Emmanuel and Berkowitz,

91 2007, Emmanuel and Ague, 2009, Emmanuel et al., 2010, Cook et al., 2011, Anovitz et al.,

92 2013a), that solubility increases in small pores due to interfacial energy effects, and that larger

93 pores, therefore, fill first. However, preliminary data also suggest that the interaction between

94 precipitate and substrate (e.g. calcite growth in controlled pore glass (CPG), functionalized CPG

95 or limestone, Stack et al., 2014), varying geochemical parameters (pressure, temperature,

96 compositions, etc., Wang et al., 2013) and nonuniformity in the flow field (Noiriel et al., 2012,

97 Molins et al., 2012) can dramatically affect pore filling (Stack et al., 2014). Ising models suggest

98 that the optimum pore size for precipitation may depend on saturation state and pore geometry

99 (Hedges and Whitelam, 2012, 2013). It is apparent that precipitation in porous media is a 
100 complex process that is still poorly understood. In addition, available analysis (Anovitz et al., 101 2013a) suggests that the surface fractal dimension is pore-size dependent. This, in turn, would 102 suggest a size-dependent variation in the number density of available nucleation sites. In-situ 103 observations of nucleation and precipitation reactions, correlated with their rates, may help 104 identify fundamental principles governing the precipitation process.

105 Annealing processes during precipitation and recrystallization can also play an important 106 role in the evolution of pore structure. Wong et al. (1986) noted that if the fluid is "clean" (i.e. 107 pure water) roughness is controlled by the competition between thermal fluctuations and surface 108 tension. This is analogous to the roughening of domains walls in the pure Ising model which 109 predicts a transition temperature $\left(\mathrm{T}_{\mathrm{r}}\right)$ above which roughening occurs even under equilibrium 110 conditions (cf. Chui and Weeks, 1981, Barabási and Stanley, 1995). Random contamination of 111 growth sites by impurities in pore fluids can lower $\mathrm{T}_{\mathrm{r}}$, analogous to results obtained from 112 random-field Ising models (Wong, 1985), and the roughening of domain walls by thermal 113 fluctuations in the atomistic nonequilibrium model (Barabási and Stanley, 1995). Similarly, 114 Cohen (1987) noted that sedimentary rocks appear to behave in a manner significantly different 115 from that expected for sintered material, including formation of fractally rough grain boundaries. 116 He suggests this "anti-sintering” behavior is caused by reduction of grain/pore free energy due to 117 interaction with pore waters. A similar effect was observed by Anovitz et al. (2009) in contact 118 metamorphosed Hueco limestone.

119 The purpose of this paper, therefore, is to investigate the controls on pore-filling 120 processes under experimentally controlled conditions. To do so we have taken samples of the 121 relatively pure St. Peter Sandstone of different initial porosity and exposed them under static, 122 externally buffered conditions, to quartz-oversaturated solutions at 100 and $200^{\circ} \mathrm{C}$ for periods 
123 ranging from three days to 7.5 months. Although a great deal is know about the factors that

124 control the dissolution and precipitation rates of quartz (cf. Dove and Rimstidt, 1994, Dove,

125 1999, Dove et al., 2005, 2008), we interrogated how these depend on, and affect the pore

126 structure of, the matrix in which precipitation occurs. We have, therefore, experimentally grown

127 quartz overgrowths in a sandstone matrix, and used a combination of small and ultra-small angle

128 neutron scattering and electron imaging techniques to examine qualitatively and quantitatively

129 the processes by which quartz precipitation occurs.

\subsection{Experimental Techniques}

\section{$134 \quad$ 2.1 Starting Materials}

135 Starting materials consisted of two samples of St. Peter sandstone from southwestern 136 Wisconsin: 04Wi17b and 05Wi30 (Kelly et al., 2007, Anovitz et al., 2013a). These were chosen

137 for their markedly varied initial porosities, with $04 \mathrm{Wi} 17 \mathrm{~b}$ containing only about $4.8 \%$ porosity, 138 and $05 \mathrm{Wi} 30$ containing $25.8 \%$ initial porosity, the difference being due to the presence of 139 substantial, optically continuous silica overgrowths in the former. Both were otherwise nearly 140 pure quartz arenites, containing only very small amounts of calcite and iron-oxide. In both cases

141 the experimental samples were cut from small samples of the initial rock $\left(<\sim 1 \mathrm{in}^{3}\right)$ with no 142 obvious inhomogeneities to assure that the starting samples for each experiment were as 143 consistent as possible. Further descriptions of the origin and chemistry of these samples are 144 provided by Kelly et al. (2007) and Anovitz et al. (2013). 
146 respect to the solubility of quartz, 2) that contained a significant quantity of dissolved silica, and

1473 ) in which the solubility was relatively independent of temperature. As the solubility of silica in

148 water is essentially independent of $\mathrm{pH}$ at low $\mathrm{pH}$ values, this meant a high-pH solution was

149 required. The solubility of quartz and amorphous silica over a range of $\mathrm{NaOH}$ concentrations

150 was calculated from the data of Wesolowski et al. (2004). At concentrations between about 0.1

151 and 0.5 molal $\mathrm{NaOH}$ the solubilities of both amorphous silica and quartz are nearly temperature-

152 independent. As a higher $\mathrm{NaOH}$ concentration increases the silica solubility we selected one near

153 the upper limit of this range for our experiments.

154 To make the starting solution we placed $3.19 \mathrm{~g}$ of Cab-o-Sil fumed silica, $78.0447 \mathrm{~g}$ of

$155 \mathrm{H}_{2}{ }^{18} \mathrm{O}$, and $21.9540 \mathrm{~g}$ of $\mathrm{D}_{2} \mathrm{O}$ (isotopic results will not be presented here) in a quartz-glass liner

156 into a $300 \mathrm{~cm}^{3}$, bolt-closure pressure vessel. As both the liner and the Cab-o-Sil were composed

157 of amorphous silica dissolution of the liner during the experiment should have no effect on the

158 solution. The $\mathrm{H}_{2} \mathrm{O} / \mathrm{D}_{2} \mathrm{O}$ mixture was sparged with Ar prior to the experiment to remove dissolved

$159 \mathrm{CO}_{2}$. The vessel was then placed in the furnace of our high-temperature emf cell (cf. Davis et al., 160 2011), heated to $150^{\circ} \mathrm{C}$ and stirred with a glass-magnet stir bar. We then titrated $50 \mathrm{~cm}^{3}$ of $161 \quad 1.3545$ molam (moles/kg solution) $\mathrm{NaOH}$ into the solution at temperature using a manually162 operated Ruska syringe pump. The resulting solution, with a final $\mathrm{NaOH}$ concentration of 0.460 163 molal was then left to stir at temperature overnight (approximately 18 hours), quenched and 164 stored in a sealed HDPE bottle. For this $\mathrm{NaOH}$ concentration the final silica concentration in 165 equilibrium with amorphous silica at $25^{\circ} \mathrm{C}$ should be approximately 0.45 molal. The measured 166 value, 0.65 molal was slightly high, but may represent either minor contamination of the 
167 analyzed fluid with solid silica, or enhanced solubility due to the fine particle size of the Cab-o-

168 Sil. In either case, however, the concentration remains satisfactory for our experiments.

169 The measured $\mathrm{pH}$ of the solution was 11.88. If we assume that all of the silica is in

170 solution as $\mathrm{H}_{3} \mathrm{SiO}_{4}^{-}$, as would be expected at this $\mathrm{pH}$ (Busey and Mesmer, 1977, Xiong 2013),

171 and correct for the effect of ionic strength on the dissociation constant of water (Busey and

172 Mesmer, 1978) we can calculate an expected $\mathrm{pH}$ of 11.84 . These values are in very good 173 agreement, well within the uncertainties of the calculation and the measurement.

\section{$175 \quad 2.2$ Experimental Approaches}

176 Two slightly different, but essentially similar approaches were used to conduct the quartz

177 precipitation experiments at 100 and $200^{\circ} \mathrm{C}$. For the $100^{\circ} \mathrm{C}$ experiments $5 / 8$ " OD, $1 / 2$ " ID quartz

178 glass tubes were prepared with one end sealed. Approximately 0.15 grams of Cab-o-Sil were 179 then added, topped by a small plug of silica glass wool. These were followed by blocks of both 180 sandstone starting materials in each tube (weights varied from 0.28 to $1.13 \mathrm{~g}$ ) and sufficient fluid 181 to more than cover the blocks (exact weights are given in Table 1). These were then frozen, 182 evacuated, thawed, refrozen, repumped to remove air from the sandstone pores and then refrozen 183 to avoid solution loss while the sample was sealed with a torch. The tubes were then bundled 184 together with a thermocouple, wrapped in insulation, and placed in an air furnace. Samples were 185 pulled from this bundle at pre-designated times and allowed to air-cool.

186 The procedures for the $200^{\circ} \mathrm{C}$ experiments were similar to those for the $100^{\circ} \mathrm{C}$ runs, 187 except that samples (blocks of both sandstones plus solution) were placed in Teflon-lined, VCR188 based stainless steel vessels that were then placed in a cold vacuum oven to remove air and then 189 inserted into an aluminum block using Pt RTDs (Resistance Temperature Detectors) to monitor 
190 the temperature (cf. Anovitz et al., 2004). For the $200^{\circ} \mathrm{C}$ experiments the reaction vessels were

191 rapidly quenched in cool water on removal from the oven. In both cases vessels were opened

192 sequentially at times ranging from 3 days to 7.5 months (see Table 1 for times), the fluids were

193 saved for analysis (Table 2), and the sandstone blocks were placed in deionized water overnight

194 before drying to limit silica precipitation during dryout.

195

$196 \quad 2.3$ Analytical Approaches

197 The analytical approaches are essentially those we have reported elsewhere (Anovitz et al., 2009, 198 2011, 2013a,b, Wang et al., 2013) and will, therefore, only be briefly summarized. Small and 199 ultrasmall angle neutron scattering were used to probe porosity over length scales from 200 approximately $10 \mathrm{~nm}$ to $30 \mu \mathrm{m}$. This was expanded to scales up to approximately $1 \mathrm{~cm}$ using 201 autocorrelation functions calculated from backscattered electron (BSE) images taken on a 202 scanning electron microscope (SEM) at 10 and 20x of the samples. Transmission electron 203 microscopy (TEM), electron diffraction (ED), and cathodoluminescence (CL) imaging were also 204 used to examine porosity and the structure of new as well as diagenetic overgrowths.

205 Small angle neutron scattering (SANS) measurements were conducted on the NG7 instrument 206 at the Center for Neutron Research at the National Institute of Standards and Technology 207 (NIST/NCNR; Glinka et al., 1998), and the General Purpose SANS Instrument at the High Flux 208 Isotope Reactor at the Oak Ridge National Laboratory (HFIR; Littrell et. al., 2008). SANS 209 measurements were performed on polished thin sections ( $0.15 \mathrm{~mm}$ thick) of each sample with the 210 beam incident along the surface normal. Because of the experimental limitations somewhat 211 smaller samples were used than those previously reported (Anovitz et al., 2009, 2013a). For 212 variable sample sizes we used cadmium masks with different size openings that allowed neutrons 
213 to access the sample: $1 / 8$ " and $1 / 4$ " round, and 0.3 " x 0.2 " and 0.5 " x 0.2 " rectangular dimensions.

214 At NIST, the wavelength $(\lambda)$ was $8.09 \AA$ with a wavelength spread $(\Delta \lambda / \lambda)$ of 0.11 . Three sample-

215 to-detector distances (1.0, 4.0 and $15.3 \mathrm{~m})$ were used to increase the observed angular range and,

216 therefore, the Q-range. Typical Q-resolution was between 5 and 10 percent depending on Q and

217 the sample-to-detector distance. At the $15.3 \mathrm{~m}$ distance we used a set of biconcave $\mathrm{MgF}_{2}$ lenses

218 to further increase the Q range and provide better overlap with the USANS data at lower Q (Choi

219 et al., 2000). The resultant scattering vector ranged from 0.0009 to $0.43 \AA^{-1}$, which corresponds to

220 sizes from approximately 15 to $7000 \AA$. At HFIR, three sample-to-detector distances (1.1, 4.7 and

$22119.3 \mathrm{~m}$ ) were used with the wavelength $\lambda=4.75 \AA$ at 1.1 and $4.7 \mathrm{~m}$, and $\lambda=19 \AA$ at $19.3 \mathrm{~m}$ with

222 a wavelength spread $\Delta \lambda / \lambda=0.14$. The measurements were performed with the detector offset to

223 extend the Q range measured at each setting and provide better overlap between settings. The

224 resultant scattering vector ranged from 0.0009 to $0.9 \AA^{-1}$, which corresponds to sizes from

225 approximately 7 to $7000 \AA$. Data were corrected for empty-beam scattering, background counts

226 and detector uniformity, sample transmission and scattering volume, and reduced to an absolute

227 scale (differential scattering cross-section per unit volume) by normalization to the intensity of

228 the direct beam. The two-dimensional data were always isotropic, and thus were circularly

229 averaged to produce one-dimensional intensity profiles (Kline, 2006).

230 Ultra-small angle neutron scattering (USANS) measurements were performed on the BT5

231 instrument at the Center for Neutron Research at the National Institute of Standards and

232 Technology (Barker et al., 2005). A pair of triple-bounce channel-cut perfect silicon (220)

233 crystals was used in this instrument for the monochromator and analyzer. The wavelength was

$2342.38 \AA$ with a wavelength spread $\Delta \lambda / \lambda=0.059$. Data were collected over a Q range from $4.19 \mathrm{x}$

$23510^{-5}$ to $2.66 \times 10^{-3} \AA^{-1}$, which corresponds to length scales from $0.24 \mu \mathrm{m}(2400 \AA)$ to $15 \mu \mathrm{m}$. The 
236 horizontal Q resolution (full width at half maximum) is $2.5 \times 10^{-5} \AA^{-1}$. The same cadmium

237 sample apertures used for the SANS measurements were used for the USANS measurements

238 which, therefore, probed the identical volume. Scattering intensity data were corrected for empty

239 beam and constant background levels. The corrected data were converted to an absolute scale by

240 measuring the attenuation of the direct beam through the sample. Further data reduction and de-

241 smearing were accomplished through the USANS data reduction software provided by

242 NIST/NCNR (Kline, 2006). The combination of USANS and SANS allows us, in principle, to

243 probe length scales over four orders of magnitude from $7 \AA$ to $15 \mu \mathrm{m}$.

244 Specimens for examination in the TEM were prepared by first impregnating samples of

245 the sandstones with epoxy. Samples were then extracted using a Hitachi NB-5000 FIB-SEM

246 focused-ion-beam instrument and imaged using a Hitachi HF-3300 cold-field-emission TEM,

247 operated at $300 \mathrm{kV}$ accelerating voltage at the High Temperature Materials Laboratory at ORNL.

248 Bright-field images were recorded on a Gatan 2K Ultrascan CCD camera.

249 Backscattered electron images of the pore space were used to extend the scattering curve

250 to larger scales and to provide two-dimensional information on the lacunarity and multifractal

251 spectrum of the pore system (Debye et al., 1957, Anovitz et al., 2013, Wang et al., 2013). Images

252 were obtained using a Hitachi S3400 environmental SEM. The samples were not coated, and a

253 pressure of $50 \mathrm{~Pa}$ was used to eliminate charging. Images were obtained at 10, 20 and in some

254 cases 40x, the first yielding an image size of $12.7 \mathrm{~mm}$ x $9.5 \mathrm{~mm}$. The images consisted of $5120 \mathrm{x}$

2553840 pixels, yielding a pixel edge length of 2.480 microns. Thus the maximum pixel size

256 overlapped the maximum spacing observable by USANS by approximately one order of

257 magnitude. Cathodoluminescence images were obtained on a similar Hitachi S3400 SEM also 
running at a pressure of $50 \mathrm{~Pa}$ on uncoated samples, using a Gatan PanaCL system with a

259 parabolic mirror in the Department of Geoscience at the University of Wisconsin-Madison.

260 Fluid chemistries were analyzed using a Varian model GTA120/AA240Z graphite-

261 furnace atomic absorption spectrometer (GFAA). Standards were made by diluting 1000 ppm Si

262 and Fe standards (Fisher lot 102251 and 102053 respectively) with DI water for Si, and 0.2 wt\%

$263 \mathrm{HNO}_{3}$ for Fe. Si was diluted to a range from $\sim 27$ to $134 \mathrm{ppb}$, and Fe from $\sim 3$ to $15 \mathrm{ppb}$. Samples

264 were diluted twice for $\mathrm{Si}$ and once for Fe with DI water as necessary to reach the linear range in

265 the GFAA.

266

267

3.0 Experimental Results and Discussion

268

269

270

271

272

273

274

275

276

277

278

279

280

\subsection{Scanning and Transmission Electron Microscope Imaging and X-ray diffraction}

Figures 1-4 show selected SEM/BSE images of different samples from the four experimental conditions run for varying lengths of time. There are several trends observable in these images. From three days and onward newly-formed overgrowths begin to be visible along grain edges and, especially in the $100^{\circ} \mathrm{C}$ experiments, finer material begins to fill the pores, a result which is likely to increase the number of small pores detected in the scattering. The formation of this finer material is less evident, however, in the $05 \mathrm{Wi30}$ (25.8\% initial porosity) experiments than in those using the $04 \mathrm{Wi17b}$ (4.8\% initial porosity) starting material.

Most surprisingly, however, in sample 04Wi17 there is a distinct increase in the porosity between the starting material and the sample after three days at both $100^{\circ} \mathrm{C}$ and $200^{\circ} \mathrm{C}$. Therefore these experiments did not exhibit the simple decrease expected in pore volume with time in the early stages of reaction. Careful examination of Figure 1a shows that pre-existing overgrowths are visible in BSE mode around many of the grains, and many of these have 
281 disappeared after 3 days (Figure 1b). This would suggest these are a different material from the 282 core (i.e. original detrital) quartz grains. However, Kelly et al. (2007) noted that the diagenetic 283 overgrowths in these samples are optically continuous with the quartz cores. Their identification 284 as quartz would also seem to be supported by the crystal faces observable on fractured surfaces 285 on overgrowth surfaces in pores (Figure 5), and when seen in cross section (Figure 5b) the 286 overgrowths are smoother and show less visible porosity at this scale than that observable in the 287 core grains.

288 There are, however, several reasons besides the dissolution behavior to argue that these 289 pre-existing overgrowths are not identical to the cores of the quartz grains. Figure 6 shows a 290 cathodoluminescent (CL) image of the sample. There are clearly multiple layers of overgrowths 291 present, some of which appear to be fibrous, whereas others do not. The latter appear to be 292 largely at the exterior surface of each grain, which may explain the features observed in the SEM 293 images (Figure 5). Griffin (2000) has noted that charge contrast imaging (CCI) in the SEM under 294 environmental conditions may yield images identical to those obtained by CL, and that "high 295 sensitivity, low kV BSE detectors are also light sensitive and consequently also will respond to 296 this phenomenon in varying degrees". This may explain the contrast observed in the BSE images. 297 Thus both the SEM and CL images are consistent in identifying the pre-existing overgrowths as 298 differing from the core quartz grains. We tested this hypothesis by conducting selected area 299 diffraction on both the core and pre-existing overgrowth materials using the TEM, but beam 300 focusing appeared to amorphize the sample, although this effect was much more severe in the 301 overgrowths than in the grain cores. This was not observed for samples of Brazilian quartz 302 analyzed on the same instrument under the same conditions. Similar results have been previously 303 reported by Mclaren and Phakey (1965a,b), van Aken et al. (1998), Stenina (2004) and Page et 
al. (2004) who suggested this phenomenon could be due to water and/or trace elements dissolved

305 in the quartz, or the presence of a truly amorphous phase, either of which could explain the 306 observed dissolution during the experiment.

307 TEM imaging was also used to examine the structure of the precipitation products at finer 308 scales. Figure 7 shows TEM images and TEM/energy dispersive analysis (EDA) X-ray maps of 309 the precipitate in sample $04 \mathrm{Wi17B}$ run at $100^{\circ} \mathrm{C}$ for 7.5 months. Most of the precipitate is platy, 310 and primarily consists of silicon and oxygen, as would be expected. This habit is common in 311 opal-CT (Graetsch, 1994, Keene, 2006, Gaillou et al., 2008), as well as at coarser scales in 312 epithermal gold deposits where it is thought to be a pseudomorph after calcite (Lindgren, 1933;

313 Urashima, 1956; Simmons and Browne, 1990, Simeone and Simmons, 1999; Simon et al., 1999,

314 Etoh et al., 2002), which is not a likely origin here. It has also been observed in phytoliths in 315 fossil forests (Kodama et al., 1992). As shown by electron diffraction (Figure 7G), however, the 316 plates are crystalline, and thus not opal, and analysis of the pattern shows that they are composed 317 of alpha-quartz. However, some opal spheres (Figure 7H) are present, and electron diffraction 318 shows that these are, indeed amorphous (Figure 7I). These data suggest that the experimental 319 silica may have originally precipitated as opal, then recrystallized to quartz. A small Na-bearing 320 layer on the plate surface suggests that some sodium hydroxide or silicate may have precipitated 321 during the quench.

322 At $200^{\circ} \mathrm{C}$ (Figure 8) at least two phases appear to be present: silica, and a Na-Fe-silicate. 323 XRD analysis of the sample as a whole shows no evidence of the presence of either aegerine, an 324 amphibole, or any other phase, although one could be present in percentages too small to be 325 observed, or the material may be amorphous. This phase undoubtedly formed by incorporating 326 small amounts of iron during dissolution and reprecipitation, but as this was quite small and 
327 some remained in solution (Table 2) the total abundance of this material in the pores is,

328 therefore, quite small as well and unlikely to affect the scattering results.

\section{$330 \quad 3.2$ Fluid Chemistry}

331 Figure 9 and Table 2 show the silica composition of the fluid (post quench) in each

332 experiment as a function of time. At $200^{\circ} \mathrm{C}$ the solution begins at or near equilibrium with 333 amorphous silica and, over time, approaches equilibrium with quartz. Although amorphous silica

334 was still present in each experiment, the fluid seems to have equilibrated more easily with the 335 quartz, perhaps due to consolidation or crystallization of the Cab-o-Sil. The results of the $100^{\circ} \mathrm{C}$ 336 experiments are, however, significantly different. Although the silica concentrations in some 337 samples rise to the level expected for quartz solubility, most have concentrations that are 338 significantly below that expected for equilibrium with either quartz, amorphous silica, or some 339 mixture thereof. The most likely explanation is that this is a quench phenomenon caused by the

340 fact that the $100^{\circ} \mathrm{C}$ experiments were run in quartz glass tubes, whereas the $200^{\circ} \mathrm{C}$ experiments 341 were performed in Teflon-lined steel vessels. At $100^{\circ} \mathrm{C}$ silica may have metastably adsorbed on 342 the quartz glass, silica wool, or amorphous silica surface. In this case, it would be the higher 343 concentration samples that more closely reflect conditions during the experiment.

\section{$345 \quad$ 3.3 Scattering Curves}

346 Figure 10 shows Porod-transformed, background-subtracted scattering data (including the 347 results from the image processing at larger scales) for selected times for each experimental 348 condition and material. Several features of the scattering curves are clear from these diagrams. 349 As we have shown previously (Anovitz et al., 2009, 2013) scattering data provide a 
350 quantification of the surface and mass fractal dimensions, and thus the surface roughness and

351 size dependent number density of potential nucleation sites, and interpore distribution of pore

352 structures. In a Porod plot smooth surfaces should yield a zero slope, surface fractals slopes fall

353 between 0 and 1, mass fractals exhibit slopes between 1 and 2, and slopes greater than 2 are

354 indicative of fuzzy interfaces. It is clear that none of these data sets can be simply described by

355 only one of these models. Instead, each appears to be composed of several steps and changes in

356 slope at different Q ranges, and both the position and intensity of these steps varies with time.

357 This is similar to the results we reported for samples of the St. Peter sandstone from SW

358 Wisconsin which contain varying levels of porosity due to overgrowth formation (Anovitz et al.,

359 2013a). Thus, at least to a first approximation, the results of the experimental quartz precipitation

360 experiments are consistent with those for the natural samples.

361 Both the SEM/BSE imagery and the (U)SANS scattering data can be used to obtain the

362 porosity of the samples. For the SEM imagery this is, of course, obtained directly from the pore

363 fraction in the binary images. For the scattering curves porosity is obtained from the invariant

364 (Y) as:

$365 \quad Y \equiv \int_{0}^{\infty} Q^{2} I(Q) d Q=2 \pi^{2}(\Delta \rho)^{2} \phi(1-\phi)$

366 assuming a two-phase (rock, pore) approximation (Radlinski, 2006), where $\Delta \rho$ is the difference

367 in scattering length density between the quartz $\left(4.18^{*} 10^{-6} \AA^{-2}\right.$ ) and the empty pores (assumed to

368 be zero), and $\phi$ is the porosity. Figure 11 and Table 1 show the changes in the (U)SANS scale,

369 image-scale, and total porosity as a function of time, although it is important to point out that

370 there is significant overlap between the image and (U)SANS scales. We observe that porosity

371 initially increases in the two 04Wi17b samples due to the dissolution mentioned above, and then

372 decreases in all four cases as precipitation occurs at larger scales with little absolute change in 
373 small-scale porosity. Fitted curves are shown for the USANS and total pore fractions to better

374 show the trends. Although at small scales there is significant scatter attributable to the small

375 absolute values, it is apparent that, with the exception of $04 \mathrm{Wi} 17 \mathrm{~b}$ at $200^{\circ} \mathrm{C}$ there has been a

376 significant decrease in both the larger and smaller-scale porosity in all four experiments. In fact,

377 the percentage change at this scale is as large or larger than that at bigger scales. This suggests

378 that, on a percentage basis, the smallerpores are filling more rapidly than larger ones, although

379 the mass of precipitated material is likely larger at larger scales.

380 In order to examine this effect in more detail we need to quantify porosity as a function of

381 pore size. As we have previously shown (Anovitz et al. 2013a,b, Wang et al., 2013) the

382 scattering curves shown in Figure 10 can be modified to extract cumulative porosity as a

383 function of pore diameter. However, we can take this one step further by taking the derivative of

384 the cumulative porosity as a function of $r$ (normalized to account for variations in step size so

385 that the integral is equal to the cumulative porosity). This yields the pore volume distribution as a

386 function of pore diameter. These results are summarized for selected reaction times for each set

387 of experiments in Figures 12-15.

388 To quantify these changes the data must be fitted as the sum of several pore distributions. The

389 choice of distributions is, however, somewhat arbitrary. Although the data could be fitted

390 assuming either a suite of log-normal distributions or a combination of fractal distributions

391 modified slightly by small log-normal sets, following our previous work (Anovitz et al., 2013a)

392 we have selected the second approach. The log-normal probability distribution functions are 393 given as:

$394 \quad V(\mathrm{r})_{\mathrm{LN}}=\frac{I}{r \sigma \sqrt{2 \pi}} e^{-\frac{(\ln r-\mu)^{2}}{2 \sigma^{2}}}$ 
395 where $\mathrm{I}$ is the overall intensity of the distribution, $\mathrm{r}$ is the pore radius, $\mathrm{e}^{\mu}$ is the median of the

396 distribution, and $\sigma$ defines the width of the distribution. The fractal distributions are given as:

$397 \quad V(r)_{F}=I Q^{3}\left(1+\frac{\sqrt{2}}{3} Q^{2} r_{0}^{2}\right)^{\frac{D s-6}{2}}$

398 where $\mathrm{I}$ is again the intensity of the distribution and $\mathrm{r}$ the pore radius, $\mathrm{Q}$ is the scattering vector

$399(=2 \pi / \mathrm{r}), \mathrm{r}_{0}$ is a position variable for the distribution (but not the peak of the distribution), and $\mathrm{D}_{\mathrm{s}}$

400 is a surface fractal dimension the defines the low-r slope of the curve. This has the advantage of

401 describing both the nature of the pore clusters and the individual pores making up those clusters.

402 All data were, therefore, fitted as the sum of three fractal distributions. These were modified at

403 the largest and smallest scales by log-normally distributed pore sets. This approach was adopted

404 for data at either end of the size range as there was insufficient data to constrain additional fractal

405 distributions, but is consistent with the unified approach adopted by Beaucage and co-workers

406 (Beaucage et al., 1995; 2004; Beaucage, 1995, 1996) to account for samples with scatterers at

407 multiple structural levels. Figures 12-15 show fits to the pore volume distributions for each run.

408 Fitting coefficients for all of the samples, along with $\mathrm{R}^{2}$ values for the fits are given in Table 3.

409 Examination of Figures 12-15 shows that there are clearly at least two pore-size distributions

410 for the $100^{\circ} \mathrm{C}$ and $200^{\circ} \mathrm{C}$ experiments on both sample types: one with a peak around 200

411 microns, the other with a peak near 0.5 microns. As noted above, and as shown by the dashed

412 lines in these figures, fitting shows that the larger length-scale features must be modified from a

413 strictly fractal distribution by the addition of a second, log-normal set. The fact that these largest

414 pores cannot be fitted as a strictly fractal distribution is apparent in several other datasets as well

415 (Radlinski et al., 2002, 2004; Anovitz et al., 2013a). A third fractal distribution is also apparent 
416 in most samples near 0.1 microns. Figure 16 shows the volumes of each of the fitted pore

417 distributions as a function of time for each experiment.

418 The relative volumes of each of these distributions change with time, as is evident both 419 qualitatively in the plots (Figures 12-15) and in the fitted results (Figure 16, Table 3). In sample 420 04Wi17b the volumes of all distributions increase during initial dissolution at both temperatures.

421 At $100^{\circ} \mathrm{C}$ the total volume of the both the larger-scale fractal and log-normal distributions then 422 slowly decrease. There is little apparent overall change at this scale for the $200^{\circ} \mathrm{C}$ experiments 423 after the initial dissolution out to 6.5 months, although the fitted results do show a decrease in the 424 log-normal modification. At $100^{\circ} \mathrm{C}$ the volume of the mesoscale distribution increases slowly. 425 The nanoscale distribution increases initially with overgrowth dissolution, followed by a 426 significant decrease for the first two weeks and then a slow continuous increase to values near 427 those of the starting and 3 day (after dissolution) samples. At $200^{\circ} \mathrm{C}$ the mesoscale porosity 428 increases for the first two to three weeks, followed by a decline to final values less than half 429 those observed at $100^{\circ} \mathrm{C}$. The nanoscale porosity also increases for approximately three weeks 430 and then decreases sharply, although the 6-week experiment is an exception to this rule.

431 The primary difference between the $04 \mathrm{Wi} 17 \mathrm{~b}$ and $05 \mathrm{Wi} 30$ samples is that the latter initially 432 had a smaller percentage of overgrowth on the core quartz grains, and thus little or no dissolution 433 and increase in porosity at short times. In fact, as shown in Figure 16, the overall patterns of 434 change in the various distributions are very similar between the two samples at each temperature 435 At $100^{\circ} \mathrm{C}$ there is relatively little change with time at larger scales although, again, the log436 normal modification decreases with time and the whole decreases slightly, indicating large-scale 437 pore filling. There is a slight increase in the mesoscale and nanoscale distributions although the 438 final values are not quite as large as those in 04Wi17b, possibly a result of an increase in the 
439 silica concentration in the pores of the latter caused by the initial dissolution. At $200^{\circ} \mathrm{C}$ some 440 dissolution clearly occurred in sample $05 \mathrm{Wi30}$, as porosity increased at all scales for 441 approximately 1 week (longer at the nanoscale). Porosity in the large log-normal modification 442 and the mesoscale and nanoscale distributions then decrease proportionately until the pore 443 volume distribution at 6.5 months looks very similar to that of the original sample, although

444 there may still be slightly greater porosity at the smaller scales. This is supported by the fitted 445 results, which show initial increases, followed by decreasing porosity at all three scales.

446 Most of the fractal dimensions fitted for the mesoscale distribution are extremely uncertain, as

447 the small-r end of this distribution is typically limited by the smaller-scale structures, the fractal 448 dimensions of which are similarly rendered uncertain by background effects and even smaller 449 structures. However, the largest-scale pore structures typically cover a larger range of scales than 450 the other two, and thus their fractal dimensions are better constrained. Although the upper end of 451 this distribution is largely defined by the imaging data, the fractal slope is largely controlled by 452 the USANS data set and is thus at a smaller scale than the multifractal results based on the 453 imaging data. For the $04 \mathrm{Wi} 17 \mathrm{~b}$ experiments the primary change is an initial decrease in the 454 fractal dimension from an initial value of 2.43 to a final value near 2.25 correlated with the 455 increase in porosity due to the initial dissolution. There is little change at longer times. For 456 sample 05Wi30, however, the decrease in porosity with time correlates with an increase in the 457 fractal dimension from a starting value of 2.17 to values near 2.3.

\section{$459 \quad 3.4$ Multifractal Analysis}

460 As we have shown in previous work (Anovitz et al., 2013a), in addition to calculating the 461 low-Q range of the scattering curve, SEM/BSE images of the pore structure in a sample can also 
462 be used to calculate the multifractal dimensions and lacunarity of that sample. These provide 463 information about the distributions of pixels, and therefore pores, within an image, and 464 significant quantification of the pore structure at this scale. They are, therefore, quantifiable 465 measures of the relation between porosity and permeability, as well as reactive surface area 466 within the sample. Multifractal values provide a quantification of how the image behaves if 467 magnified, and whether multiple scaling rules are present. Mandelbrot (1989), in an extension of 468 his original description of multifractal systems (Mandelbrot, 1974) notes that:

469 "The generalization of fractal sets to multifractal measures involves the passage from 470 geometric objects that are characterized primarily by one number, namely a fractal 471 dimension, to geometric objects that are characterized primarily by a function"

472 Typically, then, multifractals describe distributions that are not just present or absent, but have 473 varying fractal dimensions depending on their concentration - such as the distribution of copper 474 within an orebody (Mandelbrot, 1989), or porosity in space. There are several ways to quantify 475 this. One is the Rényi spectrum in which the distribution of the measure (porosity in our case) is 476 distorted by raising it to some arbitrary power, q, calculating the resultant fractal dimensions $477 \mathrm{D}(\mathrm{q})$ and plotting $\mathrm{D}(\mathrm{q})$ as a function of $\mathrm{q} . \mathrm{D}(0)$ in this case is equivalent to the box-counting or 478 capacity dimension, for which there is no weighting relative to the distribution of porosity. 479 Larger values of q weight the calculation in favor of more porous areas (denser distribution of 480 the measure), and values of q less than zero place greater emphasis on less porous areas (rarified 481 regions). $\mathrm{D}(\mathrm{q})$ typically either decreases with increasing values of $\mathrm{q}$ or, in the case of a simple 482 monofractal where there is no dependence of the fractal dimension on concentration, there will 483 be no change in $\mathrm{D}(\mathrm{q})$ with $\mathrm{q}$. A simple method of quantifying the extent of multifractal behavior 484 is, therefore, to calculate the difference between $\mathrm{D}(0)$ and $\mathrm{D}(\mathrm{q})$ at some higher value of $\mathrm{q}$, such as 
485 between $D(0)$ and $D(2)$. ( $(0)-D(q))$ then provides a measure of the multifractality of the 486 image. For a monofractal $\mathrm{D}(0)-\mathrm{D}(2)$ will be equal to zero, and the larger this value is the more 487 the fractal behavior is scale-dependent.

488 The lacunarity, $\Lambda$, provides a measure of the inhomogeneity or "gappiness" (from the latin 489 word lacuna, meaning a gap or a lake, which is commonly used in stratigraphic analysis for a gap 490 in the stratigraphic record at some location) of the pore structure. Lacunarity is, therefore, a 491 quantitative measure of how clustered the pore structure is, and serves as an addition to the 492 concept of fractal analysis (cf. Mandelbrot, 1983, 1994, 1995). It can also be viewed as a 493 measure of the translational homogeneity of an image. From the point of view of understanding 494 the relationship between porosity and permeability, therefore, this provides a quantification of 495 how isolated each pore, or group of pores is from others.

496 For a binary image divided into a given number of boxes of a given box size, $\varepsilon$, and grid 497 orientation, $\mathrm{g}$, the box-size specific lacunarity $(\lambda)$ is calculated from the mean, $\sigma$, and standard 498 deviation, $\mu$, of the number of pixels "turned on" in each box as:

$499 \quad \lambda_{\mathrm{e}, \mathrm{g}}=\left(\sigma_{\mathrm{e}, \mathrm{g}} / \mu_{\mathrm{e}, \mathrm{g}}\right)^{2}$

500 The overall lacunarity of the image, $\Lambda$, is then the average of the single box size lacunarities $(\lambda)$ 501 over all box sizes and grid positions. Analysis of these values is, of course, limited by the 502 resolution of the images in question.

503 In this paper multifractal calculations were performed using the Fraclac plugin version 2.5 for 504 Image (Karperien, 1999-2012). Figure 17 and Table 4 show the multifractal and lacunarity 505 results for samples from the four experimental conditions. For experiments on sample 04Wi17b 506 (Figure 17a,b) which began with significant dissolution there is an initial increase in the fractal 507 dimensions at all $\mathrm{q}$ (roughening, $\mathrm{D}(0)$ and $\mathrm{D}(2)$ shown), but a decrease in the multifractality 
$508(\mathrm{D}(0)-\mathrm{D}(2))$ and lacunarity of the samples. At the longest times, however, as the pores begin to

509 refill this pattern is reversed, with the pore network getting smoother and lacunarity and

510 multifractality increasing, an effect that is especially clearly demonstrated in the $100^{\circ} \mathrm{C}$

511 experiments. This latter pattern is also generally consistent with results from sample $05 \mathrm{Wi} 30$ in

512 which little or no initial dissolution occurred. In most of these samples the overall fractal

513 dimensions decrease with time, and both the multifractal and lacunarity behavior increase,

514 although there does not appear to be a significant increase in multifractality for the $200^{\circ} \mathrm{C}$

515 experiment on $05 \mathrm{Wi} 30$.

516

517

\subsection{Conclusions}

519 The data discussed above yield a number of multiscale observations of the process of quartz

520 precipitation in sandstone pores during these experiments. SEM and TEM imagery shows that, in

521 addition to the initial dissolution of original overgrowths in $04 \mathrm{Wi17b}$, with time quartz not only

522 precipitated on the grain edges, but as plates extending into the larger pores as well. The

523 presence of larger-pore filling precipitates likely increased the concentrations of smaller pores

524 due to the spaces between precipitate grains, explaining the increase in the nano-scale porosity at

525 the longest times.

526 Multifractal and lacunarity analysis of the SEM images showed that, as porosity decreases,

527 the overall fractal dimension $\mathrm{D}(0)$ also decreases. That is, the image-scale pores get smoother.

528 However, the multifractality (shown here as $\mathrm{D}(0)-\mathrm{D}(2)$ ) and the lacunarity increase. Thus, the

529 roughness of the pore structure becomes more scale dependent, and the pores become more

530 isolated. This is completely consistent with the observation by Anovitz et al. (2013a) that 
531 changes in image-scale fractal dimension and multifractality (given there as $\mathrm{D}(0)-\mathrm{D}\left(\mathrm{q}_{\max }\right)$ )

532 correlate with changes in porosity due to natural overgrowth formation (silcrete formation) in the

533 St. Peter Sandstone from SW Wisconsin, and thus shows a generalized relationship between

534 changes in pore structure due to overgrowth formation.

535 Interestingly, the decrease in $\mathrm{D}(0)$ with decreasing porosity observed at the image scale is 536 opposite to that observed in the larger fractal pore distributions in the scattering data. This is also 537 consistent with the results of Anovitz et al. (2013a), who found that, with increasing overgrowth 538 abundance (decreasing porosity) $\mathrm{D}(0)$ tended to decrease, and the fractal dimension obtained 539 from the scattering data increased. Thus, as overgrowths form (as porosity decreases) the pore 540 structure at the micron to centimeter scale becomes smoother and more clustered, whereas at 541 finer scales the surfaces become rougher.

542 As noted above, Wong et al. (1986) suggested that, although fractal scattering from 543 sandstones is often dominated by interstitial clay particles, for materials that precipitate from 544 solution (carbonates in their study) surface roughness is determined by the relative magnitudes of 545 surface tension and thermal fluctuations. In this case, by analogy to the pure Ising model, there 546 should be a transition temperature above which surfaces roughen with time. As the surface 547 tension is lowered by the presence of impurities in the solution, this tends to lower this transition 548 temperature (cf. Huse and Henley, 1985; Grinstein and Ma, 1983; Wong et al., 1984; Cohen and 549 Anderson, 1985, Cohen, 1987). Thus, at the smaller scales, an increase in roughness occurs 550 during quartz overgrowth formation such as that investigated here and by Anovitz et al. (2013a).

551 To the extent that the fractal dimension, or surface roughness can be viewed as a 552 configurational entropy (Nosonovsky, 2010), the differences between the behavior at larger and 553 smaller scales may be explained by a scale-dependent entropy transfer, even in an otherwise 
554 closed system. Nosonovsky and Esche (2008) note that thermal fluctuations at the nanoscale

555 require energy, which must be dissipated to maintain a constant temperature. The result is that

556 entropy is transferred from larger scales, where grains tend to grow or smooth and entropy

557 decreases, to smaller scales, where entropy increases and the surface becomes rougher.

558 The details of the pore structure at the sub-10 micron scale obtained from the scattering data

559 are also qualitatively similar to those observed in other natural sandstones. The pore structure is

560 not composed of a single, polydisperse distribution, but of several pore-size distributions with

561 maxima at different scales. Anovitz et al. (2013a) suggested that this may be the effect of smaller

562 grains filling spaces between larger ones, much in the manner of an Apollonian Gasket. While

563 sand grains are not spheres, although in a mature arkose like the St. Peter they are well rounded,

564 in a well-sorted sandstone the particles are of similar sizes, and thus leave between them pore

565 spaces that tend to fall into a defined size range. If some of these are filled by smaller-sized

566 grains a second pore distribution will be formed with a size distribution smaller than, and distict

567 from, the first. The observed correlations between the precipitate infilling and the development

568 of new or increase in the overall volume of preexisting smaller pore distributions tends to

569 support this suggestion. However, these distributions may also represent pores of different types

570 (cf. Swift et al., 2014), the prevalence of which is enhanced or diminished during

571 precipitation/dissolution processes.

572 Nelson (2009) summarized the prevailing ideas about the distribution of pore and pore-throat

573 sizes in sandstones. Summarizing data from Wardlow and Cassan (1979) he noted that pore

574 sizes, fitted as the largest inscribed circles in pores in resin casts, were typically about $1 / 2$ to one

575 order of magnitude smaller than the grain sizes of the rocks, and the pore throats an order of

576 magnitude smaller yet. The ratio observed by Wardlow and Cassan (1979) between grain sizes 
577 and pores is very consistent with that observed in tetrahedral or octahedral coordination between

578 identical spheres, where the radius ratio of the pore should be about 0.225 and 0.414 that of the

579 grains, respectively. Later work described by Nelson (2009), based largely on mercury

580 porosimetry, suggests pore throat sizes that are somewhat smaller than those suggested by

581 Wardlow and Cassan (1979), ranging from approximately 0.01 to 10 microns, which agrees very

582 well with the r-values for the mesoscale and nanoscale fractal distributions in our data $(\sim 1$

583 micron and $\sim 0.1$ micron).

584 There were significant differences in the temporal evolution of the various pore size

585 distributions for the four experiments, as well as in comparisons of the image-scale and

586 (U)SANS-scale overall porosity, beyond that due simply to the initial dissolution of overgrowths.

587 At the (U)SANS scale, it was clear that, whereas the bulk of the precipitation by mass was in the

588 larger pores, on a percentage basis, precipitation at the smaller scales was dominant. In all cases

589 the log-normal "modification" to the largest pore distribution decreases with time. It disappears

590 completely in both $100^{\circ} \mathrm{C}$ experiments by 7.5 months but is still present in both $200^{\circ} \mathrm{C}$

591 experiments at 6.5 months. There is much less relative decrease in the volume of the largest

592 fractal distribution itself, although the absolute decrease at this scale is much larger, and

593 dominates changes in the overall porosity. This is consistent with the suggestion by Stack et al.

594 (2014) that small pore filling is dominant during homogeneous precipitation. Differences in

595 reaction behavior between the $04 \mathrm{Wi} 17 \mathrm{~b}$ and $05 \mathrm{Wi} 30$ samples appear to be related primarily to

596 the initial dissolution of some of the overgrowths in $04 \mathrm{Wi17b}$, and to in-pore concentration

597 changes caused by the initial dissolution of overgrowths in 04Wi17b, which led to larger

598 porosity changes at longer times. 
Differences between the $100^{\circ} \mathrm{C}$ and $200^{\circ} \mathrm{C}$ results appear to be due to the nature of the

600 precipitation process itself. As shown in the SEM and TEM images (Figures 1-8) at the longest

601 times at $100^{\circ} \mathrm{C}$ much of the precipitate is present as platy material partially filling the larger

602 pores, but clearly creating significant meso- and nanoscale porosity between the grains. At

$603200^{\circ} \mathrm{C}$, however, the new material has clearly formed as overgrowths on the initial grains with

604 some, but limited, porosity within these newly formed parts of the sample. The cores of the

605 larger pores, however, remain largely empty. Thus, at $200^{\circ} \mathrm{C}$, much less new, fine-scale porosity

606 is formed.

607 The origins of the rest of the pore distributions can also be determined by examination of the

608 SEM and TEM images As is evident from the SEM images from which these data were derived,

609 the largest pore distribution clearly involves two pore types: large open pores, and variable-

610 length scale grain-grain boundary porosity. This may explain why the volume distribution for

611 pores in this size range cannot be described simply as either a fractal, or a log-normal

612 distribution, but can be reasonably fitted as a combination of the two. The reduction of the log-

613 normal part of this pair with time may also, then, be related to the decrease in multifractal

614 behavior and lacunarity with precipitation. Furthermore, this can be expected to affect the

615 relationship between pore bodies and pore throats, and thus the overall permeability of the

616 sample.

617 The separation between the mesoscale and nanoscale pore distributions is very clearly 618 delineated in the data for 05Wi30, but less so in that for 04Wi17b (Figures 12-15). This suggests 619 that the finer-scale distribution is partially obliterated by overgrowth formation. This is 620 supported by the results of the $200^{\circ} \mathrm{C}$ experiments in which overgrowth formation was the 621 primary deposition mechanism and, in both cases, the volume of the nanoscale fractal 
622 distribution decreased dramatically at longer times. As there is little clay in this material these

623 pores must be due to contacts between the quartz grains themselves. As they change with

624 precipitation they cannot be isolated pores, but must be connected to the pore network.

625 The form of the precipitate also provides interesting potential insights into quartz precipitation

626 in sedimentary basins. As noted above, the platy texture observed is commonly associated with

627 opal-CT, although the material tested in our experiments was alpha quartz. This suggests that the

628 silica may originally have precipitated as opal and converted during the experiment. Although

629 the experimental temperatures are higher than would be expected for silcretes (For example,

630 Kelley et al., 2007 suggested that quartz cementation in the samples of the St. Peter sandstone

631 from southwestern Wisconsin later examined by Anovitz et al., 2013 occurred at $10-30^{\circ} \mathrm{C}$.),

632 these temperatures are within the range observed in deep sedimentary basins (e.g. North Sea,

$633170^{\circ} \mathrm{C}$, Bjørlykke and Egeberg, 1993; Illinois Basin, 200 ${ }^{\circ} \mathrm{C}$, Proffitt et al., 2013), geothermal

634 systems and elsewhere. Although opal-CT is commonly observed at temperatures up to about 70

635 to $90^{\circ} \mathrm{C}$ (Bjørlykke and Egeberg, 1993; Kameda et al., 2012) at higher temperatures it is replaced

636 by quartz, a conversion whose rate has been studied by several investigators (Ernst and Calvert,

637 1969; Stein and Kirkpatrick, 1976; Mizutani, 1977; Williams et al., 1985; Williams and Crerar,

638 1985). It has been suggested that formation of quartz from opal-CT involves

639 dissolution/reprecipitation. If, however, the crystal form in our experiments does imply that the

640 precipitate was originally opal-CT, it appears that it converted first to quartz. At sufficiently long

641 times this could be followed by dissolution/reprecipitation reducing the large surface area of the

642 platy precipitate.

643 In summary, then, the experiments described here have shown that, even for a relatively 644 simple, nearly monomineralic, static system, the multiscalar evolution of the pore structure 
during burial diagenesis can be quite complex. Pore structures in sandstones are composed of

646 several pore-size distributions, changes in each of which can affect others, possibly leading to

647 feedback mechanisms transferring entropy between scales. In addition, it is clear that both

648 absolute and relative pore filling rates have to be considered. The effects of additional factors

649 such as fluid composition and flow, heterogeneous precipitation stress/strain etc. remain to be

650 addressed, but will surely further complicate this picture.

\subsection{Acknowledgements}

654 Effort by LMA, GR and LFA was supported by research sponsored by the Division of Chemical 655 Sciences, Geosciences, and Biosciences, Office of Basic Energy Sciences, U.S. Department of 656 Energy. DRC was funded by the Department of Energy Office of Basic Energy Sciences, 657 Division of Chemical Sciences, Geosciences and Biosciences through the Energy Frontier 658 Research Center - Nanoscale Control of Geologic $\mathrm{CO}_{2}$. We acknowledge the support of the 659 National Institute of Standards and Technology, Center for Neutron Research, U.S. Department 660 of Commerce, and the High-Flux Isotope Reactor at the Oak Ridge National Laboratory in 661 providing the research neutron facilities used in this work. This work utilized facilities supported 662 in part by the National Science Foundation under agreement No. DMR-0944772. Certain 663 commercial equipment, instruments, materials and software are identified in this paper to foster 664 understanding. Such identification does not imply recommendation or endorsement by the 665 National Institute of Standards and Technology, the Department of Energy, or the Oak Ridge 666 National Laboratory, nor does it imply that the materials or equipment identified are necessarily 667 the best available for the purpose. John Valley, Mike Spicuzza, Anthony Pollington, and Brian 668 Hess at the University of Wisconsin- Madison provided samples as part of research sponsored by 669 the Division of Chemical Sciences, Geosciences and Biosciences, Office of Basic Energy 670 Sciences, U.S. Department of Energy under contract 93ER14389 at the University of Wisconsin 671 - Madison. Help and comments from Dr. Hsiu-Wen Wang were greatly appreciated. Atomic 672 Adsorption analyses were performed by Leslie Wilson at ORNL. We would also like to thank 673 Dr. Michael Schmid, Institut für Angewandte Physik, Technische Universität Wien, for his help 674 with the ImageJ plugins for calculating the autocorrelation functions and scattering curves from 675 the BSE images.

676 
679 Anovitz, L. M., Elam, J. M., Riciputi, L. R., Cole, D. R. (2004) Isothermal time-series determination of the rate of diffusion of water in Pachuca obsidian. Archaeometry, 46, 301-326.

682

683

684

685

686

687

688

689

690

691

692

693

694

695

696

697

698

699

700

701

702

703

704

705

706

707

708

709

710

711

712

713

714

715

716

717

Anovitz, L. M., Lynn, G. W., Cole, D. R., Rother, G., Allard, L. F., Hamilton, W. A., Porcar, L., Kim, M-H. (2009) A new approach to quantification of metamorphism using ultra-small and small-angle neutron scattering. Geochim. Cosmochim. Acta 2009, 73, 7303-7324.

Anovitz L. M., Rother G. and Cole D. R. (2011) Characterization of rock pore features in geothermal systems using small angle neutron scattering (SANS). In Proc. 36th Workshop on Geothermal Reservoir Engineering. Stanford Univ., Stanford, SGP-TR-191.

Anovitz L. M., Cole D. R., Rother G., Allard L. F., Jackson A. J. and Littrell K. C. (2013a) Digenetic changes in macro- to nano-scale porosity in the St. Peter Sandstone: An (ultra) small angle neutron scattering and backscattered electron imaging analysis. Geochim. Cosmochim. Acta 102, 280-305.

Anovitz, L. M., Wang, H.-W., Cole, D. R., Sheets, J., Rother, G., Faulder, D. D., Walters M. (2013b) Analysis of multiscale porosity at the Coso geothermal field. Proc. $38^{\text {th }}$ Workshop On Geothermal Res. Eng., SPG-TR-198.

Barabasi, S.-L., Stanley, H. E. (1995) Fractal Concepts in Surface Growth. Cambridge University Press.

Barker J. G., Glinka C. J., Moyer J. J., Kim M. H., Drews A. R. and Agamalian M. (2005) Design and performance of a thermal-neutron double-crystal diffractometer for USANS at NIST. J. Appl. Crystallogr. 38, 1004-1011.

Beaucage G. (1995) Approximations leading to a unified exponential/power-law approach to small-angle scattering, J. Appl. Cryst. 28, 717-728.

Beaucage, G., Ulibarri, T. A., Black, E. P., and Schaefer, D. W. (1995) Multiple size scale structures in silica- siloxane composites studied by small-angle scattering. In: Hybrid Organic-Inorganic Composites, ACS Symposium series 585, Mark, JE, Lee, C Y-C, Bianconi, PA (Eds.), Ch. 9, 97-111.

Beaucage, G., Kammler, H. K., Pratsinis, S. E. (2004) Particle size distributions from smallangle scattering using global scattering functions. J. Appl. Cryst. 37, 523-535.

Beaucage, G. (1996) Small-angle scattering from polymeric mass fractals of arbitrary massfractal dimension, J. Appl. Cryst. 29, 134-146.

Busey, R. H. and Mesmer, R. E. (1977) Ionization Equilibria of Silicic Acid and Polysilicate Chloride Solutions to $300^{\circ} \mathrm{C}$. Inorganic Chemistry 16, $2444-24508$

Busey, R. H. and Mesmer, R. E. (1977) Thermodynamic Quantities for the Ionization of Water in Sodium Chloride Media to $300{ }^{\circ} \mathrm{C}$. Journal of Chemical and Engineering Data, 23, 175 -176 .

Choi S. M., Barker J. G., Glinka C. J., Cheng Y. T. and Gammel P. L. (2000) Focusing cold neutrons with multiple biconcave lenses for small-angle neutron scattering. J. Appl. Crystallogr. 33, 793-796. 
Chui, S. T., and Weeks, J. D. (1981) Pinning and roughening of one-dimensional models of interfaces and steps. Phys. Ref. B 23(5), 2438-2441.

Cohen M. H. (1987) The morphology of porous sedimentary rocks. In: Physics and Chemistry of Porous Media II. AIP Conf. Proc., 154, 3-16.

Cohen, M. H. and Anderson, M. P. (1985) Geometry and topology of porous materials. In: The Chemistry and Physics of Composite Media, edited by M. Tomkiewicz and P. N. Sen (The Electrochemical Society, Pennington, New Jersey), 1-10.

Cook J. E., Goodwin L. B. and Boutt D. F. (2011) Systematic diagenetic changes in the grainscale morphology and permeability of a quartz-cemented quartz arenite. AAPG Bulletin 95, 1067-1088.

Davis M. C., Wesolowski D. J., Rosenqvist J., Brantley S. L. and Mueller K. T. (2011) Solubility and near-equilibrium dissolution rates of quartz in dilute $\mathrm{NaCl}$ solutions at $398-473 \mathrm{~K}$ under alkaline conditions. Geochimica et Cosmochimica Acta 75, 401-415.

Dove, P. M. (1999) The dissolution kinetics of quartz in aqueous mixed cation solutions. Geochim. Cosmochim. Acta, 63, 3715-3727.

Dove, P. M. and Rimstidt, JD (1994) Silica-water interactions. In: Silica: Physical Behavior, Geochemistry and Materials Applications, Reviews in Mineralogy 29, Ch. 8, 259-308.

Dove, P. M., Han, N. Z., De Yoreo, J> J. (2005) Mechanisms of classical crystal growth theory explain quartz and silicate dissolution behavior. Proc. Nation. Acad. Sci 102, 1535715362.

Dove, P. M., Han, N, Wallace, A. F., and De Yoreo, J. J. (2008) Kinetics of amorphous silica dissolution and the paradox of the silica polymorphs. Proc. Nation. Acad. Sci 105, 99039908.

Emmanuel, S., Ague, J. J., Walderhaug, O. Interfacial energy effects and the evolution of pore size distributions during quartz precipitation in sandstone. Geochim. Cosmochim. Acta 2010, 74, 3539- 3552 .

Emmanuel, S., Ague, J. J. (2009) Modeling the impact of nano-pores on mineralization in sedimentary rocks. Water Resour. Res. 2009, 45, W04406.

Emmanuel, S., Berkowitz, B. Effects of pore-size controlled solubility on reactive transport in heterogeneous rock. Geophys. Res. Lett. 2007, 34, L06404.

Ernst, W. G. and Calvert, S. E. (1969) An experimental study of the recrystallization of porcelanite and its bearing on the origin of some bedded cherts. Am. J. Sci 267-A, 114133.

Etoh, J., Izawa, E., Watanabe, K. (2002) Bladed quartz and its relationship to gold mineralization in the Hishikari low-sulfidation epithermal gold deposit, Japan. Economic Geology, 97, 1841-1851.

Gaillou E., Fritsch E., Aguilar-Reyes B., Rondeau B., Barreau A., Ostroumov M. (2008) Common gem opal: An investigation of micro- to nano-structure. American Mineralogist, vol. 93, pp. 1865-1873.

Glinka C. J., Barker J. G., Hammouda B., Krueger S., Moyer J. J. and Orts W. J. (1998) The 30 
m small-angle neutron scattering instruments at the National Institute of Standards and Technology. J. Appl. Crystallogr. 31, 430-445.

Griffin, B. J. (2000) Charge contrast imaging of material growth and defects in environmental scanning electron microscopy-linking electron emission and cathodoluminescence. Scanning, 22(4), 234-242.

Graetsch, H. (1994) Structural characteristics of opaline and microscrystaline silica minerals. In: Silica: Physical Behavior, Geochemistry and Materials Applications, Reviews in Mineralogy, Vol. 29, Ch. 6, 209-232.

Grinstein, G. and Ma, S.-K. (1983) Surface tension, roughening, and lower critical dimension in the random-field Ising model. Phys. Rev. B, 28, 2588-2601.

Hedges, L. O., Whitelam, S. (2012) Patterning a surface so as to speed nucleation from solution. Soft Matter. 8 (33), 8624-8635.

Hedges, L. O., Whitelam, S. (2012) Selective nucleation in porous media. Soft Matter, 9, 97639766.

Huse, D. and Henley, C. L. (1985) Pinning and roughening of domain walls in Ising systems due to random impurities. Phys. Rev. Lett. 54, 2708-2711.

$\begin{array}{llllll}\text { Karperien, } & \text { A. (1999-2012) FracLac for ImageJ, version } 2.5 .\end{array}$ http://rsb.info.nih.gov/ij/plugins/fraclac/FLHelp/Introduction.htm.

Keene, J. B. (2006) Cherts and porcellanites from the North Pacific, DSDP leg 32. Deep Sea Drilling Reports Vol. 32, Ch. 14., 429-507.

Kelly, J. L., Fu, B., Kita, N. T., Valley, J. W. (2007) Optically continuous silcrete quartz cements of the St. Peter sandstone: high precision oxygen isotope analysis by ion microprobe. Geochim. Cosmochim. Acta 2007, 71, 3812-3832.

Kline S. R. (2006) Reduction and analysis of SANS and USANS data using IGOR Pro. J. Appl. Crystallogr. 39, 895-900.

Kodama, H., Fox, C.A., Tarnocai, C., and Longstaffe, F. J. (1992) Platy quartz phytoliths found in the fossil forests deposits, Axel Heiberg Island, Northwest Territories, Canada. Zeit. für Pflanzenernähr. Bodenk. 155, 401-6.

Lindgren, W. (1933) Mineral deposits, 4th edition: New York, McGraw-Hill, 930 p.

Littrell K. C., Atchley K. M., Cheng G., Melnichenko Y. B. and Wignall G. D. (2008) General purpose small-angle neutron scattering instrument on HFIR Oak Ridge. Neutron News 19(3), 20-21.

Mandelbrot, B. B. (1974) Intermittent turbulence in self similar cascades; divergence of high moments and dimension of the carrier, J. Fluid Mech 62, 331-358.

Mandelbrot, B. B. (1983) The Fractal Geometry of Nature. (New York: W.H. Freeman).

Mandelbrot, B. B. (1989) Multifractal measures, especially for the geophysicist. Pageoph 131, 542.

Mandelbrot, B. B. (1994) A fractal's lacunarity, and how it can be tuned and measured. In: Fractals in Biology and Medicine, eds TF Nonnenmacher, GA Losa, ER Weibel (Basel 
and Boston: Birkhäuser Verlag).

Mandelbrot B. B. (1995) Measures of fractal lacunarity: Minkowski content and alternatives". Fractal Geometry and Stochastics, eds C Bandt, S Graf, and M Zähle (Basel and Boston: Birkhäuser Verlag).

McLaren, A. C., and Phakey, P. P. (1965a) Dislocations in quartz observed by transmission electron microscopy. J. Appl. Phys. 36(10), 3244-3246.

McLaren, A. C., and Phakey, P. P. (1965b), Transmission electron microscope study of amethyst and citrine. Aust. J. Phys., 18, 135-141.

Mizutani, S. (1977) Progressive ordering of cristobalitic silica in the early stage of diagenesis. Contrib. Mineral. Petrol., 61, 129-140.

Molins, S., Trebotich, D., Steefel, C. I., Shen, C. (2012) An investigation of the effect of pore scale flow on average geochemical reaction rates using direct numerical simulation. Water Resour. Res., 48.

Nelson, P. H. (2009) Pore-throat sizes in sandstones, tight sandstones, and shales. AAPG Bull. 93 (3), 329-340.

Noiriel, C., Steefel, C. I., Yang, L., Ajo-Franklin, J. (2012) Upscaling calcium carbonate precipitation rates from pore to continuum scale. Chem. Geol., 318-319, 60-74.

Nosonovsky, M. (2010) Entropy in tribology: in the search for applications. Entropy, 12, 13451390.

Nosonovsky, M. and Esche, S. K. (2008) A paradox of decreasing entropy in multiscale Monte Carlo grain growth simulations. Entropy, 10, 49-54.

Page, K. L., Proffen, Th., McLain, S. E., Darling, T. W., and TenCate, J. A. (2004) Local atomic structure of Fontainebleau sandstone: Evidence for an amorphous phase? Geophys. Res. Lett., 31, L24606.

Putnis, A., Mauthe, G. (2001) The effect of pore size on cementation in porous rocks. Geofluids, $1,37-41$.

Radlinski, A. P. (2006) Small-angle neutron scattering and the microstructure of rocks. Rev. Mineral. Geochem., 63, 363-397.

Radlinski, A., Ioannidis, M., Hinde, A., Hainbuchner, M., Baron, M., Rauch, H., Kline, S. (2002) Multiscale characterization of reservoir rock microstructure: combining smallangle neutron scattering and image analysis. SCA2002-35, Proceedings of 2002 International Symposium of the Society of Core Analysts, 22-25.

Radlinski, A., Ioannidis, M., Hinde, A., Hainbuchner, M., Baron, M., Rauch, H., Kline, S. (2004) Angstrom-to-millimeter characterization of sedimentary rock microstructure. J. Colloid Interface Sci. 2004, 274, 607-612.

Simon, G., Kesler, S. E., Ressell, N., Hall, C. M., Bell, D., and Piñero, E. (1999) Epithermal gold mineralization in an old volcanic arc: The Jacinto deposit, Camagüey district, Cuba: Economic Geology, v. 94, p. 487-506.

Simeone, R., and Simmons, S. F. (1999) Mineralogical and fluid inclusion studies of lowsulfidation epithermal veins at Osilo (Sardinia), Italy: Mineralium Deposita, v. 34, p. 
705-717.

Simmons, S. F., and Browne, P. R. L. (1990) Mineralogic, alteration, and fluid- inclusion studies of epithermal gold-bearing veins at the Mt. Muro Prospect, Central Kalimantan (Borneo), Indonesia; Journal of Geochemical Exploration, v. 35, p. 63-103.

Stack, A. G., Fernandez-Martinez, A., Allard, L. F., Bañuelos, J. L., Rother, G., Anovitz, L. M., Cole, D.R., and Waychaunas, G. A. (2014) Pore-size dependent calcium carbonate precipitation in mesoporous silica controlled by surface-chemistry. Environ. Sci Technol. 48, 6177-6183.

Stein, C. L. and Kirkpatrick, R. J. (1976) Experimental porcelanite recrystallization kinetics: a nucleation and growth model. J. Sed. Pet. 46, 430-435.

Stenina, N. G. (2004) Water-related defects in quartz. Bull. Geosci., 79(4), 251-268.

Swift, A., Anovitz, L. M. Sheets, J. M. Cole, D. R., Welch, S., and Rother, G. (2014) Relationship between mineralogy and porosity in seals relevant to geologic $\mathrm{CO}_{2}$ sequestration. Environmental Geosciences, 21, 39-57.

Urashima, Y. (1956) "Bosa" quartz veins, especially the fine-grained quartz aggregates, of the Konomai mine in Hokkaido, Japan: Hokkaido University, Journal of Faculty of Science, 9, 371-387.

van Aken, P. A., Sharp, T. G., and Seifert, F. (1998) Electron-beam induced amorphization of stishovite: Silicon-coordination change observed using Si K-edge extended electron energy-loss fine structure. Phys. Chem. Min., 25, 83-93.

Wang, H.-W., Anovitz, L. M., Burg, A., Cole, D. R., Allard, L. F., Jackson, A. J., Stack, A. G., and Rother, G. (2013) Multi-scale characterization of pore evolution in a combustion metamorphic complex, Hatrurim basin, Israel: Combining (ultra) small-angle neutron scattering and image analysis. Geochim. Cosmochim. Acta 121, 339-362.

Wardlaw, N. C., and Cassan, J. P. (1979) Oil recovery efficiency and the rock-pore properties of some sandstone reservoirs. Bulletin of Canadian Petroleum Geology, v. 27, no. 2, p. 117138.

Wesolowski, D.J.; Ziemniak, S.E.; Anovitz, L.M.; Machesky, M.L.; Bénézeth, P.; Palmer, D.A. (2004) Solubility and Surface Adsorption Characteristics of Metal Oxides, in (D.A. Palmer, R. Fernandez-Prini and A.H. Harvey, eds.) Aqueous Systems at Elevated Temperatures and Pressures, Elsevier, London, 493-595.

Williams, L. A., Parks, G. A., and Crerar, D. A. (1985) Silica diagenesis, I. Solubility controls. J. Sed. Pet. 55, 301-311.

Williams, L. A., and Crerar, D. A. (1985) Silica diagenesis, II. General Mechanisms. J. Sed. Pet. $55,312-321$.

Wong, P.-Z. (1985) Scattering by inhomogeneous systems with rough internal surfaces - Porous Solids and Random-Field Ising Systems. Phys. Rev. B, 32, 7417-7424.

Wong, P.-Z., Cable, J. W. and Dimon, P. (1984) Experimental studies of random field effects in uniaxial random antiferromagnets. J. Appl. Phys. 55, 2377-2382. 
876 Wong, P.-Z., Howard, J., and Lin, J.-S. (1986) Surface roughening and the fractal nature of 877 rocks. Phys. Rev. Lett. 57, 637-640.

878 Xiong, Y (2013) A thermodynamic model for silica and aluminum in alkaline solutions with 879 high ionic strength at elevated temperatures up to $100{ }^{\circ} \mathrm{C}$ : Applications to zeolites. 880 American Mineralogist, 98, 141-153.

881

882 
885 Figure 1: SEM/BSE images of selected samples of sample 04Wi17b run for a) 0 days, b) 3 days,

c) 8 weeks and d) 7.5 months at $100^{\circ} \mathrm{C}$. Arrows show several areas of precipitate. Individual image width $=3.175 \mathrm{~mm}$. Width of insert images in $(\mathrm{c})$ and $(\mathrm{d})=0.793 \mathrm{~mm}$.

Figure 2: SEM/BSE images of selected samples of sample 04Wi17b run for a) 0 days, b) 3 days, Image width $=3.175 \mathrm{~mm}$.

Figure 3: SEM/BSE images of selected samples of sample 05Wi30 run for a) 0 days, b) 3 days, width $=3.175 \mathrm{~mm}$.

894 Figure 4: SEM/BSE images of selected samples of sample $05 \mathrm{Wi30}$ run for a) 0 days, b) 3 days, c) 6 weeks, 2 days and d) 6.5 months at $200^{\circ} \mathrm{C}$. Arrows show several areas of precipitate. Image width $=3.175 \mathrm{~mm}$.

Figure 5: Secondary electron images of overgrown quartz grains in the starting 04Wi17b material showing well-formed crystal faces. Note the apparent porosity differences between the overgrowths and the core detrital quartz grains at this scale.

900 Figure 6: Cathodoluminescent (CL) image of sample 04Wi17b. There are clearly multiple layers 901 of overgrowths present, some of which appear to be fibrous, whereas others do not. Image 902 obtained on a Hitachi S-3400 scanning electron microscope at $20 \mathrm{kV}$ and an air pressure of $90350 \mathrm{~Pa}$ equipped with a Gatan PanaCL system with a parabolic mirror. The image is approximately $1.27 \mathrm{~mm}$ across, and pixel size is 0.496 microns.

905 Figure 7: TEM images and TEM/EDA X-ray maps of the precipitate in sample 04Wi17B run at 906 $100^{\circ} \mathrm{C}$ for 7.5 months. A) image of initial FIB sample take across one of the partially filled 
large pores. B, C) TEM images of $\mathrm{SiO}_{2}$ plates deposited in the pore, D) Si map, E), O map,

F) Na map, G) electron diffraction image of silica plates showing indexing as alpha quartz, H) opal sphere, I) electron diffraction image of opal sphere shown in (H).

910 Figure 8: TEM images and TEM/EDA X-ray maps of the precipitate in sample 04Wi17B run at

$911200^{\circ} \mathrm{C}$ for 6.5 months. A, B) Images showing the presence of a second (brighter, rice-

912 shaped) material. C, D, E, F) Si, O, Na, Fe maps showing that this second phase appears to 913 be a sodium iron silicate.

914 Figure 9: Silica composition of the fluid (post quench) in each experiment as a function of time.

915 As samples of $04 \mathrm{Wi17b}$ and $05 \mathrm{Wi} 30$ were run together in each reaction vessel to assure that

916 each saw the same fluid composition, temperature, and time, there are only two sets of 917 analyses, one for each temperature. Solid circles $\left(100^{\circ} \mathrm{C}\right)$, open circles $\left(200^{\circ} \mathrm{C}\right)$, solid lines 918 equilibrium solubility of amorphous $\mathrm{SiO}_{2}$ at the experimental $\mathrm{pH}$, dashed lines, equilibrium 919 solubility of quartz at the experimental $\mathrm{pH}$.

920 Figure 10: Selected, Porod-transformed, background-subtracted scattering data (including the 921 results from the image processing at larger scales) for selected times for each experimental 922 condition and material. Data are offset for clarity. Note the changes in step size and position 923 and the slope of the background curve. A) $04 \mathrm{Wi} 17 \mathrm{~b}, 100^{\circ} \mathrm{C}$, solid squares (starting material), 924 open squares (3 day), solid circles (8 weeks), open circles (7.5 months); B) 04Wi17b, $200^{\circ} \mathrm{C}$, 925 solid squares (starting material), open squares (3 day), solid circles (6 weeks, 2 days), open 926 circles $\left(6.5\right.$ months); C) $05 \mathrm{Wi} 30,100^{\circ} \mathrm{C}$, solid squares (starting material), open squares (3 927 day), solid circles (8 weeks), open circles (6.5 months); D) $05 \mathrm{Wi} 30,200^{\circ} \mathrm{C}$, solid squares 928 (starting material), open squares (3 day), solid circles (6 weeks, 2 days), open circles (6.5 929 months); 
930 Figure 11: Changes in porosity at the (U)SANS scale (triangles), image-scale (open circles), and 931 total porosity (squares) as a function of time. The (U)SANS porosity is calculated from the 932 invariant of the scattering data without addition of data points from the imaging 933 calculations. The image-scale data is obtained from the binary transformation of the image 934 used to define the pore structure. A) $\left.\left.04 \mathrm{Wi} 17 \mathrm{~b}, 100^{\circ} \mathrm{C}, \mathrm{B}\right) 04 \mathrm{Wi} 17 \mathrm{~b}, 200^{\circ} \mathrm{C}, \mathrm{C}\right) 05 \mathrm{Wi} 30$, $\left.935100^{\circ} \mathrm{C}, \mathrm{D}\right) 05 \mathrm{Wi} 30,200^{\circ} \mathrm{C}$. As zero time cannot be represented on a log time scale the 936 starting values are shown as grey symbols at 1 day.

937 Figure 12: Pore volume distributions for samples of $04 \mathrm{Wi17b}$ run at $100^{\circ} \mathrm{C}$. A) starting material, $938 \quad$ B) 3 days, C) 8 weeks, D) 7.5 months. The solid line is the total fit, the dashed lines show 939 the individual fitted distributions. The asymmetrical dashed lines are the fractal 940 distributions, the symmetrical dashed lines are the log-normal distributions.

941 Figure 13: Pore volume distributions for samples of $04 \mathrm{Wi1} 7 \mathrm{~b}$ run at $200^{\circ} \mathrm{C}$. A) starting material, $942 \quad$ B) 3 days, C) 6 weeks, 2 days, D) 6.5 months. The solid line is the total fit, the dashed lines 943 show the individual fitted distributions. The asymmetrical dashed lines are the fractal 944 distributions, the symmetrical dashed lines are the log-normal distributions.

945 Figure 14: Pore volume distributions for samples of $05 \mathrm{Wi} 30$ run at $100^{\circ} \mathrm{C}$. A) starting material, 946 B) 3 days, C) 7 weeks, D) 7.5 months. (note that because the 8 week sample was small the 947 data were more scattered and were not fitted). The solid line is the total fit, the dashed lines 948 show the individual fitted distributions. The asymmetrical dashed lines are the fractal 949 distributions, the symmetrical dashed lines are the log-normal distributions.

950 Figure 15: Pore volume distributions for samples of $05 \mathrm{Wi} 30$ run at $200^{\circ} \mathrm{C}$. A) starting material, 951 B) 3 days, C) 6 weeks, 2 days D) 6.5 months. The solid line is the total fit, the dashed lines 
952 show the individual fitted distributions. The asymmetrical dashed lines are the fractal 953 distributions, the symmetrical dashed lines are the log-normal distributions.

954 Figure 16: Volumes of each of the fitted pore volume distributions as a function of time. A) $\left.\left.\left.955 \quad 04 \mathrm{Wi} 17 \mathrm{~b}, 100^{\circ} \mathrm{C}, \mathrm{B}\right) 04 \mathrm{Wi} 17 \mathrm{~b}, 200^{\circ} \mathrm{C}, \mathrm{C}\right) 05 \mathrm{Wi} 30,100^{\circ} \mathrm{C}, \mathrm{D}\right) 05 \mathrm{Wi} 30,200^{\circ} \mathrm{C}$. Solid 956 squares (largest fractal distribution), open circles, (large log-normal distribution), open 957 squares (mesoscale fractal distribution), solid circles (nanoscale fractal distribution). As zero 958 time cannot be represented on a log time scale the starting values are shown as grey symbols 959 at 1 day.

960 Figure 17: Multifractal and lacunarity results for samples from the four experimental conditions. 961 A) $04 \mathrm{Wi} 17 \mathrm{~b}, 100^{\circ} \mathrm{C}$, B) $04 \mathrm{Wi1} 1 \mathrm{~b}, 200^{\circ} \mathrm{C}$, C) $\left.05 \mathrm{Wi} 30,100^{\circ} \mathrm{C}, \mathrm{D}\right) 05 \mathrm{Wi} 30,200^{\circ} \mathrm{C}$. Solid 962 squares $(D(0))$, open circles, $(D(2))$, open squares (lacunarity), solid circles $(D(0)-D(2))$. 963 As zero time cannot be represented on a log time scale the starting values are shown as grey 964 symbols at 1 day. 
967 Table 1: Experimental conditions, sample weights, times, temperatures, USANS and imaging $968 \quad$ porosities

969 Table 2: fluid Chemistries

970 Table 3: fitting coefficients

971 Table 4: Multifractal and Lacunarity results 
Table 1: Experimental Conditions and Pore Volumes

\begin{tabular}{|c|c|c|c|c|c|c|c|c|c|c|c|}
\hline Sample & $\begin{array}{c}\mathrm{T} \\
\left({ }^{\circ} \mathrm{C}\right) \\
\end{array}$ & $\begin{array}{l}\text { Time } \\
\text { (days) }\end{array}$ & $\begin{array}{c}\text { sample } \\
\text { wt (gms) }\end{array}$ & $\begin{array}{l}\text { fluid wt } \\
\text { (gms) } *\end{array}$ & $\begin{array}{l}\text { Image } \\
\text { Magnif }\end{array}$ & $\begin{array}{l}\text { Image } \\
\text { pore } \\
\text { fraction }\end{array}$ & $\begin{array}{c}\text { Invariant } \\
\text { Volume } \\
\text { Total } \\
\end{array}$ & $\begin{array}{l}\text { Invariant } \\
\text { Volume } \\
\text { (U)SANS }\end{array}$ & $\begin{array}{c}\% \\
\text { Change } \\
\text { total } \\
\end{array}$ & $\begin{array}{c}\% \\
\text { Change } \\
\text { (U)SANS }\end{array}$ & $\begin{array}{c}\% \\
\text { Change } \\
\text { image } \\
\end{array}$ \\
\hline 04Wi17b & 0 & 0 & & & 10 & 0.0500 & 0.0551 & 0.0149 & -70.25 & -56.06 & -71.66 \\
\hline 04Wi17b & 100 & 3 & 0.578 & 1.266 & 10 & 0.1764 & 0.1854 & 0.0352 & 0.00 & 0.00 & 0.00 \\
\hline 04Wi17b & 100 & 3 & & & 20 & 0.1652 & & & & & -6.37 \\
\hline 04Wi17b & 100 & 7 & 1.015 & 1.892 & 10 & 0.1643 & 0.1667 & 0.0266 & -10.06 & -42.23 & -6.88 \\
\hline 04Wi17b & 100 & 7 & & & 20 & 0.1571 & & & & & -10.97 \\
\hline 04Wi17b & 100 & 14 & 0.724 & 1.875 & 10 & 0.1544 & 0.1561 & 0.0233 & -15.78 & -41.49 & -12.45 \\
\hline 04Wi17b & 100 & 14 & & & 20 & 0.1550 & & & & & -12.13 \\
\hline 04Wi17b & 100 & 21 & 0.929 & 1.726 & 10 & 0.1286 & 0.1383 & 0.0261 & -25.41 & -46.80 & -27.07 \\
\hline 04Wi17b & 100 & 21 & & & 20 & 0.1385 & & & & & -21.49 \\
\hline 04Wi17b & 100 & 28 & 0.961 & 1.884 & 10 & 0.1366 & 0.1383 & 0.0244 & -25.42 & -45.82 & -22.57 \\
\hline 04Wi17b & 100 & 28 & & & 20 & 0.1333 & & & & & -24.46 \\
\hline 04Wi17b & 100 & 35 & 1.130 & 1.845 & 10 & 0.1362 & 0.1425 & 0.0262 & -23.12 & -34.88 & -22.78 \\
\hline 04Wi17b & 100 & 35 & & & 20 & 0.1349 & & & & & -23.54 \\
\hline 04Wi17b & 100 & 42 & 1.050 & 2.012 & 10 & 0.1238 & 0.1276 & 0.0214 & -31.15 & -55.42 & -29.81 \\
\hline 04Wi17b & 100 & 42 & & & 20 & 0.1264 & & & & & -28.34 \\
\hline 04Wi17b & 100 & 42 & & & 40 & 0.1352 & & & & & -23.37 \\
\hline 04Wi17b & 100 & 49 & 1.030 & 1.782 & 10 & 0.1360 & 0.1424 & 0.0266 & -23.18 & -29.44 & -22.89 \\
\hline 04Wi17b & 100 & 56 & 1.000 & 1.418 & 10 & 0.1340 & 0.1573 & 0.0260 & -15.13 & -35.71 & -24.06 \\
\hline 04Wi17b & 100 & 56 & & & 20 & 0.1297 & & & & & -26.49 \\
\hline 04Wi17b & 100 & 228 & 0.940 & 1.654 & 10 & 0.0633 & 0.0738 & 0.0238 & -60.20 & -33.56 & -64.10 \\
\hline 04Wi17b & 100 & 228 & & & 20 & 0.0537 & & & & & \\
\hline 04Wi17b & 0 & 0 & & & 10 & 0.0500 & 0.0551 & 0.0149 & -63.37 & -57.47 & -63.73 \\
\hline 04Wi17b & 200 & 3 & 1.092 & 6.409 & 10 & 0.1378 & 0.1340 & 0.0268 & -10.98 & -32.14 & 0.00 \\
\hline 04Wi17b & 200 & 3 & & & 20 & 0.1330 & & & & & -3.53 \\
\hline 04Wi17b & 200 & 7 & 0.898 & 4.388 & 10 & 0.1295 & 0.1506 & 0.0311 & 0.00 & -13.78 & -6.07 \\
\hline 04Wi17b & 200 & 7 & & & 20 & 0.1238 & & & & & -10.20 \\
\hline 04Wi17b & 200 & 15 & 1.135 & 3.845 & 10 & 0.1217 & 0.1334 & 0.0256 & -11.42 & -32.20 & -11.69 \\
\hline 04Wi17b & 200 & 15 & & & 20 & 0.1177 & & & & & -14.63 \\
\hline 04Wi17b & 200 & 21 & 0.905 & 5.024 & 10 & 0.1134 & 0.1322 & 0.0359 & -12.17 & 0.00 & -17.77 \\
\hline 04Wi17b & 200 & 21 & & & 20 & 0.1103 & & & & & -19.97 \\
\hline 04Wi17b & 200 & 29 & 1.879 & 5.406 & 10 & 0.1171 & 0.1317 & 0.0272 & -12.55 & -21.62 & -15.02 \\
\hline 04Wi17b & 200 & 29 & & & 20 & 0.1080 & & & & & -21.66 \\
\hline 04Wi17b & 200 & 35 & 1.995 & 5.301 & 10 & 0.1120 & 0.1268 & 0.0284 & -15.80 & -35.89 & -18.74 \\
\hline 04Wi17b & 200 & 35 & & & 20 & 0.1202 & & & & & -12.79 \\
\hline 04Wi17b & 200 & 44 & 1.543 & 4.938 & 10 & 0.1112 & 0.1280 & 0.0309 & -15.00 & -24.45 & -19.33 \\
\hline 04Wi17b & 200 & 44 & & & 20 & 0.1095 & & & & & -20.56 \\
\hline 04Wi17b & 200 & 198 & 1.578 & 4.545 & 10 & 0.1154 & 0.1246 & 0.0252 & -17.25 & -44.20 & -16.28 \\
\hline $04 \mathrm{Wi17b}$ & 200 & 198 & & & 20 & 0.1127 & & & & & -18.21 \\
\hline 05Wi30 & 0 & 0 & & & 10 & 0.1600 & 0.1467 & 0.0310 & -5.97 & -11.62 & 0.00 \\
\hline 05Wi30 & 100 & 3 & 0.565 & 1.266 & 10 & 0.1469 & 0.1561 & 0.0267 & 0.00 & -23.08 & -8.19 \\
\hline 05Wi30 & 100 & 3 & & & 20 & 0.1482 & & & & & -7.39 \\
\hline 05Wi30 & 100 & 7 & 0.738 & 1.892 & 10 & 0.1495 & & & & & -6.58 \\
\hline 05Wi30 & 100 & 7 & & & 20 & 0.1372 & & & & & -14.24 \\
\hline 05Wi30 & 100 & 14 & 1.043 & 1.875 & 10 & 0.1406 & 0.1444 & 0.0228 & -7.46 & -30.65 & -12.13 \\
\hline
\end{tabular}




\begin{tabular}{|c|c|c|c|c|c|c|c|c|c|c|c|}
\hline 05Wi30 & 100 & 21 & 0.692 & 1.726 & 10 & 0.1409 & & & & & -11.93 \\
\hline 05Wi30 & 100 & 28 & 0.804 & 1.884 & 10 & 0.1288 & 0.1307 & 0.0238 & -16.25 & -31.60 & -19.52 \\
\hline 05Wi30 & 100 & 35 & 0.562 & 1.845 & 10 & 0.1190 & 0.1259 & 0.0242 & -19.31 & -29.84 & -25.63 \\
\hline 05Wi30 & 100 & 35 & & & 20 & 0.1141 & & & & & -28.69 \\
\hline 05Wi30 & 100 & 42 & 0.831 & 2.012 & 10 & 0.1254 & 0.1434 & 0.0361 & -8.15 & 0.00 & -21.61 \\
\hline 05Wi30 & 100 & 42 & & & 20 & 0.1318 & & & & & -17.61 \\
\hline 05Wi30 & 100 & 49 & 0.608 & 1.782 & 10 & 0.1267 & 0.1353 & 0.0261 & -13.29 & -30.21 & -20.84 \\
\hline 05Wi30 & 100 & 49 & & & 20 & 0.1186 & & & & & -25.89 \\
\hline 05Wi30 & 100 & 56 & 0.279 & 1.418 & 10 & 0.0833 & 0.0987 & 0.0248 & -36.74 & -97.55 & -47.94 \\
\hline 05Wi30 & 100 & 56 & & & 20 & 0.1033 & & & & & -35.42 \\
\hline 05Wi30 & 100 & 228 & 0.569 & 1.654 & 10 & 0.1154 & 0.1310 & 0.0393 & -16.09 & -61.64 & -27.86 \\
\hline $05 \mathrm{Wi} 30$ & 100 & 228 & & & 20 & 0.1288 & & & & & -19.48 \\
\hline 05Wi30 & 0 & 0 & & & 10 & 0.1600 & 0.1467 & 0.0310 & -11.62 & -41.61 & 0.00 \\
\hline 05Wi30 & 200 & 3 & 1.098 & 6.409 & 10 & 0.1418 & 0.1522 & 0.0319 & -8.31 & -28.16 & -11.36 \\
\hline 05Wi30 & 200 & 7 & 0.349 & 4.388 & 10 & 0.1389 & 0.1660 & 0.0465 & 0.00 & 0.00 & -13.16 \\
\hline 05Wi30 & 200 & 7 & & & 20 & 0.1314 & & & & & -17.90 \\
\hline 05Wi30 & 200 & 15 & 1.057 & 3.845 & 10 & 0.1346 & 0.1494 & 0.0341 & -10.04 & -27.47 & -15.90 \\
\hline 05Wi30 & 200 & 15 & & & 20 & 0.1328 & & & & & -17.02 \\
\hline 05Wi30 & 200 & 21 & 1.505 & 5.024 & 10 & 0.1317 & 0.1577 & 0.0452 & -5.00 & -21.78 & -17.71 \\
\hline 05Wi30 & 200 & 21 & & & 20 & 0.1344 & & & & & -15.98 \\
\hline 05Wi30 & 200 & 29 & 1.767 & 5.406 & 10 & 0.1378 & 0.1514 & 0.0343 & -8.82 & -41.22 & -13.86 \\
\hline 05Wi30 & 200 & 29 & & & 20 & 0.1251 & & & & & -21.83 \\
\hline 05Wi30 & 200 & 35 & 0.717 & 5.301 & 10 & 0.1336 & 0.1364 & 0.0271 & -17.83 & -98.54 & -16.48 \\
\hline 05Wi30 & 200 & 35 & & & 20 & 0.1318 & & & & & -17.61 \\
\hline 05Wi30 & 200 & 44 & 0.789 & 4.938 & 10 & 0.1357 & 0.1505 & 0.0345 & -9.33 & -27.94 & -15.21 \\
\hline 05Wi30 & 200 & 44 & & & 20 & 0.1289 & & & & & -19.44 \\
\hline 05Wi30 & 200 & 198 & 0.776 & 4.545 & 10 & 0.1222 & 0.1300 & 0.0250 & -21.68 & -59.27 & -23.60 \\
\hline 05Wi30 & 200 & 198 & & & 20 & 0.1207 & & & & & -24.58 \\
\hline
\end{tabular}

* one reaction vessel contained both the $04 \mathrm{Wi} 17 \mathrm{~b}$ and $05 \mathrm{Wi} 30$ samples for each temperature and time 
Table 2: Post experiment fluid chemistry

\begin{tabular}{|l|c|r|}
\hline Sample & \multicolumn{1}{l|}{$\begin{array}{l}\text { molality } \\
\mathrm{SiO}_{2}\end{array}$} & \multicolumn{1}{l|}{ molality Fe } \\
\hline tube $1-100^{\circ} \mathrm{C}$ & $1.731 \mathrm{E}-01$ & \\
tube $2-100^{\circ} \mathrm{C}$ & $1.259 \mathrm{E}-01$ & $3.957 \mathrm{E}-04$ \\
tube $3-100^{\circ} \mathrm{C}$ & $2.463 \mathrm{E}-01$ & $7.764 \mathrm{E}-04$ \\
tube $4-100^{\circ} \mathrm{C}$ & $1.521 \mathrm{E}-01$ & $1.183 \mathrm{E}-03$ \\
tube $6-100^{\circ} \mathrm{C}$ & $1.409 \mathrm{E}-01$ & $4.632 \mathrm{E}-04$ \\
tube $7-100^{\circ} \mathrm{C}$ & $1.522 \mathrm{E}-01$ & $4.628 \mathrm{E}-04$ \\
tube $8-100^{\circ} \mathrm{C}$ & $6.552 \mathrm{E}-01$ & $3.013 \mathrm{E}-03$ \\
tube $9-100^{\circ} \mathrm{C}$ & $2.864 \mathrm{E}-01$ & $7.071 \mathrm{E}-04$ \\
tube $10-100^{\circ} \mathrm{C}$ & $1.500 \mathrm{E}-01$ & $5.026 \mathrm{E}-04$ \\
& & \\
vessel $1-200^{\circ} \mathrm{C}$ & $3.585 \mathrm{E}-01$ & $1.774 \mathrm{E}-03$ \\
vessel $2-200^{\circ} \mathrm{C}$ & $3.911 \mathrm{E}-01$ & $8.368 \mathrm{E}-04$ \\
vessel $3-200^{\circ} \mathrm{C}$ & $3.278 \mathrm{E}-01$ & $0.000 \mathrm{E}+00$ \\
vessel $4-200^{\circ} \mathrm{C}$ & $3.558 \mathrm{E}-01$ & $6.387 \mathrm{E}-04$ \\
vessel $5-200^{\circ} \mathrm{C}$ & $3.510 \mathrm{E}-01$ & $8.115 \mathrm{E}-04$ \\
vessel $6-200^{\circ} \mathrm{C}$ & $3.184 \mathrm{E}-01$ & \\
vessel $7-200^{\circ} \mathrm{C}$ & $3.003 \mathrm{E}-01$ & $9.313 \mathrm{E}-04$ \\
vessel $8-200^{\circ} \mathrm{C}$ & $3.124 \mathrm{E}-01$ & $1.723 \mathrm{E}-03$ \\
\hline
\end{tabular}


Table 3: Fitting Coefficients for individual pore distributions

\begin{tabular}{|c|c|c|c|c|c|c|c|c|c|c|c|c|c|c|c|c|c|c|c|c|c|}
\hline Sample & $\begin{array}{c}\mathrm{T} \\
\left({ }^{\circ} \mathrm{C}\right)\end{array}$ & $\begin{array}{l}\text { Time } \\
\text { (days) }\end{array}$ & $\begin{array}{l}\text { log normal } \\
\text { Intensity } 1\end{array}$ & sigma & $R($ med) & $\begin{array}{l}\text { log normal } \\
\text { Intensity } 2\end{array}$ & sigma & $R$ (med) & $\begin{array}{l}\text { Fractal } 1 \\
\text { Intensity } \\
\end{array}$ & $r$ & Ds & volume & $\begin{array}{l}\text { Fractal } 2 \\
\text { Intensity }\end{array}$ & $r$ & Ds & volume & $\begin{array}{l}\text { Fractal } 3 \\
\text { Intensity }\end{array}$ & $r$ & Ds & volume & $\mathrm{R}^{2}$ \\
\hline 04Wi17b & 0 & 0 & & & & $1.85 \mathrm{E}-02$ & $8.47 \mathrm{E}-01$ & $1.24 \mathrm{E}+07$ & $1.70 \mathrm{E}-01$ & $1.00 \mathrm{E}+03$ & 2.10 & $1.20 \mathrm{E}-06$ & $1.70 \mathrm{E}+02$ & $7.00 \mathrm{E}+03$ & 2.00 & $2.31 \mathrm{E}-05$ & $3.50 \mathrm{E}+09$ & $9.00 \mathrm{E}+05$ & 2.43 & $3.66 \mathrm{E}-02$ & $1.76 \mathrm{E}-02$ \\
\hline 04Wi17b & 0 & 3 & $2.00 \mathrm{E}-08$ & $1.00 \mathrm{E}+00$ & $00 \mathrm{E}+02$ & $69 \mathrm{E}-02$ & $5.53 \mathrm{E}-01$ & $81 E+06$ & $10 \mathrm{E}+00$ & $1.10 \mathrm{E}+03$ & 10 & $6.27 \mathrm{E}-06$ & $1.70 \mathrm{E}+02$ & $7.00 E+03$ & 2.00 & $2.32 \mathrm{E}-05$ & $2.26 \mathrm{E}+10$ & $1.01 \mathrm{E}+06$ & 2.23 & $1.66 \mathrm{E}-01$ & $.90 \mathrm{E}-02$ \\
\hline Wi17b & 0 & 7 & 50E-08 & $00 \mathrm{E}+00$ & $0 \mathrm{OE}+02$ & 00E-02 & $53 \mathrm{E}-01$ & $50 E+06$ & OOE-04 & $50 E+02$ & .00 & 7.47E-08 & $.00 \mathrm{E}+02$ & $.00 \mathrm{E}+03$ & 2.30 & $1.60 \mathrm{E}-05$ & $.21 \mathrm{E}+10$ & $.96 \mathrm{E}+05$ & 2.32 & $1.19 \mathrm{E}-01$ & $8.94 \mathrm{E}-03$ \\
\hline Wi17b & 0 & 14 & $1.00 \mathrm{E}-09$ & $00 E+00$ & $00 E+02$ & 93E-02 & $4.51 \mathrm{E}-01$ & $09 E+06$ & OOE-05 & $.00 \mathrm{E}+02$ & 2.00 & $2.85 \mathrm{E}-08$ & $.50 \mathrm{E}+01$ & $.00 E+03$ & 2.00 & $2.25 \mathrm{E}-05$ & $1.00 E+10$ & $8.00 E+05$ & 2.20 & $1.15 \mathrm{E}-01$ & 1.17E-02 \\
\hline 04Wi17b & bo & 21 & $3.00 \mathrm{E}-08$ & $00 \mathrm{E}+00$ & $2.00 E+02$ & $4.45 \mathrm{E}-02$ & $4.48 \mathrm{E}-01$ & $2.80 E+06$ & $.00 \mathrm{E}-03$ & $2.50 E+02$ & 2.00 & $1.07 \mathrm{E}-07$ & $2.75 \mathrm{E}+02$ & $7.00 E+03$ & 2.10 & $3.94 \mathrm{E}-05$ & $6.00 E+09$ & $7.00 \mathrm{E}+05$ & 2.25 & $9.31 \mathrm{E}-02$ & $1.26 \mathrm{E}-02$ \\
\hline 04Wi17b & 100 & 28 & $5.00 \mathrm{E}-08$ & $1.00 \mathrm{E}+00$ & $2.00 \mathrm{E}+02$ & $3.50 \mathrm{E}-02$ & $4.38 \mathrm{E}-01$ & $2.65 \mathrm{E}+06$ & $1.00 \mathrm{E}-03$ & $2.50 \mathrm{E}+02$ & 2.00 & 1.07E-07 & $3.50 \mathrm{E}+02$ & $7.00 E+03$ & 2.10 & $5.02 \mathrm{E}-05$ & $7.70 E+09$ & $7.50 \mathrm{E}+05$ & 2.22 & $1.02 \mathrm{E}-01$ & $1.62 \mathrm{E}-02$ \\
\hline 04Wi17b & 100 & 35 & $2.00 \mathrm{E}-08$ & $1.00 E+00$ & $2.00 E+02$ & 50E-02 & $5.44 \mathrm{E}-01$ & $2.42 E+06$ & $.00 \mathrm{E}-03$ & $2.00 \mathrm{E}+02$ & 2.00 & $1.68 \mathrm{E}-07$ & $3.00 E+01$ & $3.00 E+03$ & 2.00 & $2.23 \mathrm{E}-05$ & $1.20 E+10$ & $8.50 E+05$ & 2.20 & $1.23 \mathrm{E}-01$ & $4.48 \mathrm{E}-03$ \\
\hline 04Wi17b & 100 & 42 & & & & $2.64 \mathrm{E}-02$ & $4.64 \mathrm{E}-01$ & $2.10 \mathrm{E}+06$ & $1.70 \mathrm{E}-03$ & $2.50 \mathrm{E}+02$ & 2.00 & $1.81 \mathrm{E}-07$ & $1.50 \mathrm{E}+01$ & $3.00 \mathrm{E}+03$ & 2.00 & $1.11 \mathrm{E}-05$ & $89 \mathrm{E}+09$ & $6.92 \mathrm{E}+05$ & 2.20 & $1.06 \mathrm{E}-01$ & $2.24 \mathrm{E}-02$ \\
\hline 04Wi17b & 100 & 49 & $9.00 \mathrm{E}-09$ & $7.27 \mathrm{E}-01$ & $2.05 \mathrm{E}+02$ & $1.45 \mathrm{E}-02$ & $3.38 \mathrm{E}-01$ & $65 E+06$ & -03 & $2.50 \mathrm{E}+02$ & 2.10 & $2.24 \mathrm{E}$ & $00 \mathrm{E}+02$ & +03 & 2.20 & -05 & +10 & $9.30 \mathrm{E}+05$ & 2.30 & -01 & $9.11 \mathrm{E}-02$ \\
\hline i17b & 00 & 56 & & $1.00 \mathrm{E}+00$ & $1.00 E+02$ & & $6.00 \mathrm{E}-01$ & $1.50 \mathrm{E}+06$ & 80E-03 & $2.50 E+02$ & 2.10 & $2.02 \mathrm{E}-07$ & $5.00 \mathrm{E}+01$ & $4.00 \mathrm{E}+03$ & 2.20 & $2.32 \mathrm{E}-05$ & +10 & $9.00 E+05$ & 2.20 & $1.28 \mathrm{E}-01$ & $3.55 \mathrm{E}-02$ \\
\hline Vi17b & 100 & 228 & & & & & & & $.00 \mathrm{E}-02$ & $5.00 E+02$ & 2.40 & 2.67E-06 & $2.50 \mathrm{E}+03$ & $1.50 E+04$ & 2.50 & $9.89 \mathrm{E}-05$ & $6.50 E+09$ & $8.25 E+05$ & 2.20 & $7.07 \mathrm{E}-02$ & $9.49 \mathrm{E}-03$ \\
\hline $17 \mathrm{~b}$ & 0 & 0 & & & & & $17 \mathrm{E}-01$ & $24 \mathrm{E}+07$ & $1.70 \mathrm{E}-01$ & $1.00 E+03$ & 2.10 & $1.20 \mathrm{E}-06$ & $70 E+02$ & $7.00 E+03$ & 2.00 & $2.31 \mathrm{E}-05$ & +09 & $9.00 \mathrm{E}+05$ & 2.43 & $3.66 \mathrm{E}-02$ & 1.76 \\
\hline & 200 & 3 & & & & $3.00 \mathrm{E}-02$ & $5.50 \mathrm{E}-01$ & $2.70 E+06$ & $2.80 \mathrm{E}-01$ & $7.00 \mathrm{E}+02$ & 2.35 & 4.64E-06 & $1.00 \mathrm{E}+04$ & $2.00 E+04$ & 2.00 & $1.67 E-04$ & $7.50 \mathrm{E}+09$ & $7.50 \mathrm{E}+05$ & 2.23 & $9.99 E-02$ & $1.97 \mathrm{E}$ \\
\hline 04Wi17b & 200 & 7 & $7.80 \mathrm{E}-08$ & $1.20 \mathrm{E}+00$ & $2.00 E+02$ & $2.00 \mathrm{E}-02$ & $5.53 \mathrm{E}-01$ & $2.50 \mathrm{E}+06$ & $8.50 \mathrm{E}-01$ & $9.00 \mathrm{E}+02$ & 2.05 & $7.20 \mathrm{E}-06$ & $2.20 \mathrm{E}+03$ & $1.10 E+04$ & 2.00 & $1.21 \mathrm{E}-04$ & $9.50 E+09$ & $7.50 E+05$ & 2.23 & E-01 & $2.84 \mathrm{E}-02$ \\
\hline 04Wi17b & 200 & 15 & $7.00 \mathrm{E}-08$ & $1.20 \mathrm{E}+00$ & $2.00 \mathrm{E}+02$ & OE-02 & $5.53 \mathrm{E}-01$ & $2.00 \mathrm{E}+06$ & $3.00 \mathrm{E}+00$ & $1.40 \mathrm{E}+03$ & 2.10 & $1.07 \mathrm{E}-05$ & OOE+02 & 03 & 2.00 & & & $8.50 \mathrm{E}+05$ & 2.23 & & \\
\hline 04Wi17b & 200 & 21 & & $20 \mathrm{E}+00$ & $3.20 \mathrm{E}+02$ & 2 & $5.53 \mathrm{E}-01$ & +06 & $4.00 \mathrm{E}+00$ & $1.20 \mathrm{E}+03$ & 2.00 & $1.85 \mathrm{E}-05$ & $5.50 \mathrm{E}+03$ & +04 & 2.00 & 1.63 & +09 & $7.00 E+05$ & 2.23 & & \\
\hline 04Wi17b & 200 & 29 & $6.00 \mathrm{E}-08$ & $1.05 E+00$ & $3.16 \mathrm{E}+02$ & $1.00 \mathrm{E}-02$ & $5.53 \mathrm{E}-01$ & $3.00 \mathrm{E}+06$ & $3.81 E+00$ & $1.49 \mathrm{E}+03$ & 2.12 & $1.22 \mathrm{E}-05$ & $1.50 \mathrm{E}+03$ & +04 & 2.00 & $9.66 \mathrm{E}-05$ & +09 & $7.50 \mathrm{E}+05$ & 2.13 & -01 & $7.61 \mathrm{E}$ \\
\hline 04Wi17b & 200 & 35 & $4.50 \mathrm{E}-08$ & $1.05 E+00$ & $3.16 \mathrm{E}+02$ & $1.50 \mathrm{E}-02$ & $5.53 \mathrm{E}-01$ & $3.00 E+06$ & $2.50 \mathrm{E}-01$ & $1.00 \mathrm{E}+03$ & 2.35 & $2.02 \mathrm{E}-06$ & $2.75 E+02$ & $6.00 E+03$ & 2.00 & $5.10 \mathrm{E}-05$ & $7.50 E+09$ & $7.00 E+05$ & 2.24 & $1.16 \mathrm{E}-01$ & $1.32 \mathrm{E}-02$ \\
\hline 04Wi17b & 200 & 44 & 50E-08 & $1.05 E+00$ & $3.16 \mathrm{E}+02$ & $1.00 \mathrm{E}-02$ & $4.64 \mathrm{E}-01$ & $2.50 \mathrm{E}+06$ & $4.50 \mathrm{E}+00$ & $1.50 \mathrm{E}+03$ & 2.10 & $1.40 \mathrm{E}-05$ & $5.00 \mathrm{E}+02$ & $9.00 \mathrm{E}+03$ & 2.00 & 4.12E-05 & $9.50 \mathrm{E}+09$ & $7.70 E+05$ & 2.23 & E-01 & $3.31 \mathrm{E}-02$ \\
\hline 04Wi17b & 200 & 198 & 0E-08 & $00 \mathrm{E}+00$ & $00 \mathrm{E}+02$ & OOE-02 & $5.53 \mathrm{E}-01$ & $2.50 \mathrm{E}+06$ & $2.30 \mathrm{E}-03$ & $2.50 \mathrm{E}+02$ & 2.30 & $2.87 \mathrm{E}-07$ & $1.15 \mathrm{E}+02$ & $4.50 \mathrm{E}+03$ & 2.10 & $3.99 \mathrm{E}-05$ & $7.70 E+09$ & $7.50 \mathrm{E}+05$ & 2.23 & L.03E-01 & $6.91 \mathrm{E}-03$ \\
\hline & 0 & 0 & & & & & & & & +02 & 2.10 & & +01 & & 2.00 & & & +05 & 2.17 & & \\
\hline 05Wi30 & 100 & 3 & $3.00 \mathrm{E}-08$ & $1.20 E+00$ & $1.88 \mathrm{E}+02$ & & & & $3.20 \mathrm{E}-03$ & $3.00 \mathrm{E}+02$ & 2.10 & $2.49 \mathrm{E}-07$ & $5.90 \mathrm{E}+01$ & $4.00 \mathrm{E}+03$ & 2.00 & 2.46E-05 & $1.50 \mathrm{E}+10$ & $8.50 E+05$ & 2.20 & $1.53 \mathrm{E}-01$ & $2.24 \mathrm{E}-02$ \\
\hline & 100 & $7^{*}$ & & & & & & & & & & & & & & & & & & & \\
\hline & 100 & 14 & & 00 & 02 & & & & & & 10 & & & & 2.10 & & & & 2.20 & & \\
\hline & 100 & $2 \varepsilon$ & E-08 & $20 E+00$ & $88 \mathrm{E}+02$ & & 4.77E-01 & +06 & O0E-03 & $4.00 \mathrm{E}+02$ & 2.10 & $1.32 \mathrm{E}-07$ & $=+02$ & +03 & 2.10 & $6.86 \mathrm{E}-05$ & +09 & $=05$ & 2.20 & -01 & $1.20 \mathrm{E}-02$ \\
\hline Wi30 & 100 & 35 & OEE-08 & $20 \mathrm{E}+00$ & $88 \mathrm{E}+02$ & $2.00 \mathrm{E}-02$ & $4.64 \mathrm{E}-01$ & $2.50 \mathrm{E}+06$ & $2.00 \mathrm{E}-04$ & $1.50 E+02$ & 2.10 & $6.82 \mathrm{E}-08$ & $8.00 \mathrm{E}+01$ & $5.00 E+03$ & 2.40 & 2.66E-05 & $7.50 E+09$ & $7.20 \mathrm{E}+05$ & 2.20 & $1.07 \mathrm{E}-01$ & $1.71 \mathrm{E}-02$ \\
\hline Wi30 & 100 & 42 & 00E-08 & $20 \mathrm{E}+00$ & $88 \mathrm{E}+02$ & 07E-02 & $2.99 \mathrm{E}-01$ & $2.82 \mathrm{E}+06$ & $1.20 \mathrm{E}-03$ & $2.00 \mathrm{E}+02$ & 2.10 & $2.10 \mathrm{E}-07$ & $1.20 \mathrm{E}+03$ & $1.00 E+04$ & 2.20 & $8.90 \mathrm{E}-05$ & $1.20 \mathrm{E}+10$ & $8.70 E+05$ & 2.35 & $1.28 \mathrm{E}-01$ & $9.69 \mathrm{E}-03$ \\
\hline 05Wi30 & 100 & 49 & $9.00 \mathrm{E}-09$ & $7.27 \mathrm{E}-01$ & $2.05 E+02$ & $1.45 \mathrm{E}-02$ & $3.38 \mathrm{E}-01$ & $2.65 \mathrm{E}+06$ & $2.00 \mathrm{E}-03$ & $2.50 \mathrm{E}+02$ & 2.10 & $2.24 \mathrm{E}-07$ & $4.00 \mathrm{E}+02$ & $9.00 \mathrm{E}+03$ & 2.20 & $3.66 \mathrm{E}-05$ & $1.30 \mathrm{E}+10$ & $9.30 \mathrm{E}+05$ & 2.30 & $1.17 \mathrm{E}-01$ & $3.43 \mathrm{E}-03$ \\
\hline $05 \mathrm{Wi30}$ & 100 & $56^{*}$ & & & & & & & & & & & & & & & & & & & \\
\hline & 100 & 228 & & & & & & & & $2.58 \mathrm{E}+02$ & 2.35 & & $1.05 \mathrm{E}+02$ & $5.00 \mathrm{E}+03$ & 2.40 & $3.50 \mathrm{E}-05$ & $1.35 \mathrm{E}+10$ & $9.00 \mathrm{E}+05$ & 2.30 & & $3.16 \mathrm{E}-01$ \\
\hline & 0 & 0 & & & & & $9.36 \mathrm{E}-01$ & & & $3.50 \mathrm{E}+02$ & 2.10 & $4.03 \mathrm{E}-07$ & & $E+03$ & 2.00 & & & +05 & 2.17 & & \\
\hline & 200 & 3 & & & & & $3.75 \mathrm{E}-01$ & & $2.52 \mathrm{E}-01$ & $7.84 \mathrm{E}+02$ & 2.41 & $3.44 \mathrm{E}-06$ & $1.14 \mathrm{E}+04$ & & 2.38 & & & & 2.23 & & \\
\hline & 200 & 7 & $\mathrm{E}-08$ & $7.48 \mathrm{E}-01$ & $1.57 \mathrm{E}+02$ & & $3.75 \mathrm{E}-01$ & & $7.00 \mathrm{E}-01$ & $8.00 E+02$ & 2.06 & 7.53E-06 & $1.30 \mathrm{E}+03$ & & 2.06 & $\mathrm{E}-04$ & & $=05$ & 2.23 & & $1.96 \mathrm{E}-02$ \\
\hline & 200 & 15 & & $9.36 \mathrm{E}-01$ & 1.14E+02 & $\mathrm{E}-02$ & $3.95 \mathrm{E}-01$ & $58 \mathrm{E}+06$ & $6.50 \mathrm{E}-01$ & $9.50 \mathrm{E}+02$ & 2.00 & $4.84 \mathrm{E}-06$ & $5.00 \mathrm{E}+02$ & $8.00 \mathrm{E}+03$ & 2.00 & $5.21 \mathrm{E}-05$ & $1.03 E+10$ & $8.40 E+05$ & 2.35 & $1.18 \mathrm{E}-01$ & $2.53 \mathrm{E}-02$ \\
\hline & 200 & 21 & $\mathrm{E}-08$ & $8.15 \mathrm{E}-01$ & $1.58 \mathrm{E}+02$ & $\mathrm{E}-02$ & $3.65 \mathrm{E}-01$ & $78 \mathrm{E}+06$ & $3.20 \mathrm{E}+00$ & $1.20 \mathrm{E}+03$ & 2.05 & $1.52 \mathrm{E}-05$ & $00 E+02$ & +03 & 2.00 & $5.22 \mathrm{E}-05$ & +10 & $.00 \mathrm{E}+05$ & 2.35 & $1.39 \mathrm{E}-01$ & $9.10 \mathrm{E}-03$ \\
\hline 05Wi30 & 200 & 29 & $4.00 \mathrm{E}-08$ & $9.07 E-01$ & $2.05 \mathrm{E}+02$ & OE-02 & $4.64 \mathrm{E}-01$ & $2.50 \mathrm{E}+06$ & $5.99 \mathrm{E}-01$ & $1.06 \mathrm{E}+03$ & 2.19 & $3.91 \mathrm{E}-06$ & $7.00 \mathrm{E}+02$ & $8.50 \mathrm{E}+03$ & 2.18 & $7.10 \mathrm{E}-05$ & $1.30 \mathrm{E}+10$ & $8.50 E+05$ & 2.20 & $1.33 \mathrm{E}-01$ & $5.54 \mathrm{E}-02$ \\
\hline 05Wi30 & 200 & 35 & $4.00 \mathrm{E}-08$ & $9.07 E-01$ & $2.05 \mathrm{E}+02$ & $9.43 \mathrm{E}-03$ & $5.94 \mathrm{E}-01$ & $1.37 \mathrm{E}+06$ & $5.00 \mathrm{E}-01$ & $1.06 \mathrm{E}+03$ & 2.19 & $3.28 \mathrm{E}-06$ & $7.00 \mathrm{E}+02$ & $8.50 E+03$ & 2.18 & $7.10 \mathrm{E}-05$ & $1.30 \mathrm{E}+10$ & $8.50 E+05$ & 2.20 & $1.25 \mathrm{E}-01$ & $5.72 \mathrm{E}-02$ \\
\hline 05Wi30 & 200 & 44 & & & & $1.00 \mathrm{E}-02$ & $4.64 \mathrm{E}-01$ & $2.50 E+06$ & $5.00 \mathrm{E}-03$ & $3.00 \mathrm{E}+02$ & 2.25 & $1.18 \mathrm{E}-07$ & $2.00 \mathrm{E}+02$ & $6.00 E+03$ & 2.25 & $4.19 \mathrm{E}$ & $1.30 E+10$ & +05 & 2.30 & 1.41 & $2.82 \mathrm{E}-02$ \\
\hline 05Wi30 & 200 & 198 & & & & $6.66 \mathrm{E}-03$ & $5.23 \mathrm{E}-01$ & $1.57 E+06$ & $3.00 \mathrm{E}-03$ & $2.70 \mathrm{E}+02$ & 2.25 & $1.01 \mathrm{E}-07$ & $1.50 \mathrm{E}+02$ & $6.00 \mathrm{E}+03$ & 2.25 & $3.16 \mathrm{E}-05$ & $2.00 \mathrm{E}+10$ & $1.10 \mathrm{E}+06$ & 2.30 & $1.29 \mathrm{E}-01$ & $3.21 \mathrm{E}-02$ \\
\hline
\end{tabular}

* not fitted because data too scattered 
Table 4: Lacunarity and Multifractal Dimensions for the images

\begin{tabular}{|c|c|c|c|c|c|c|}
\hline Sample & $\begin{array}{l}\mathrm{T} \\
\left({ }^{\circ} \mathrm{C}\right)\end{array}$ & $\begin{array}{l}\text { Time } \\
\text { days }\end{array}$ & Lacunarity & $\mathrm{D}(0)$ & $\mathrm{D}(1)$ & $\mathrm{D}(2)$ \\
\hline 04Wi17b & 0 & 0 & 0.6615 & 1.5911 & 1.4657 & 1.4266 \\
\hline Wi17b & 100 & 3 & 0.3605 & 1.7719 & 1.7124 & 1.6839 \\
\hline 04Wi17b & 100 & 7 & 0.3178 & 1.7713 & 1.741 & 1.7144 \\
\hline 04Wi17b & 100 & 14 & 0.3248 & 1.7341 & 1.7266 & 1.7185 \\
\hline 04Wi17b & 100 & 21 & 0.2716 & 1.7972 & 1.7735 & 1.7502 \\
\hline 04Wi17b & 100 & 28 & 0.3226 & 1.8172 & 1.7832 & 1.757 \\
\hline 04Wi17b & 100 & 35 & 0.3817 & 1.7661 & 1.7406 & 1.7209 \\
\hline 04Wi17b & 100 & 42 & 0.3714 & 1.815 & 1.8032 & 1.7864 \\
\hline 04Wi17b & 100 & 49 & 0.2852 & 1.8164 & 1.7926 & 1.7764 \\
\hline 04Wi17b & 100 & 56 & 0.3462 & 1.7999 & 1.7875 & 1.775 \\
\hline 04Wi17b & 100 & 228 & 0.6801 & 1.7298 & 1.6329 & 1.5719 \\
\hline 04Wi17b & 0 & 0 & 0.6615 & 1.5911 & 1.4657 & 1.4266 \\
\hline 04Wi17b & 200 & 3 & 0.4797 & 1.7413 & 1.6861 & 1.6575 \\
\hline 04Wi17b & 200 & 7 & 0.392 & 1.7263 & 1.723 & 1.711 \\
\hline 04Wi17b & 200 & 15 & 0.3992 & 1.7462 & 1.708 & 1.6736 \\
\hline 04Wi17b & 200 & 21 & 0.3257 & 1.7834 & 1.7592 & 1.7431 \\
\hline 04Wi17b & 200 & 29 & 0.4052 & 1.7512 & 1.7261 & 1.7064 \\
\hline 04Wi17b & 200 & 35 & 0.3783 & 1.7345 & 1.6941 & 1.6638 \\
\hline 04Wi17b & 200 & 44 & 0.5107 & 1.7732 & 1.7477 & 1.7179 \\
\hline 04Wi17b & 200 & 198 & 0.3367 & 1.7328 & 1.6892 & 1.6628 \\
\hline 05Wi30 & 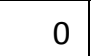 & 0 & 0.2773 & 1.7331 & 1.6785 & 1.6609 \\
\hline 05Wi30 & 100 & 3 & 0.3181 & 1.7972 & 1.7589 & 1.7291 \\
\hline 05Wi30 & 100 & 7 & 0.3639 & 1.7349 & 1.7159 & 1.7019 \\
\hline 05Wi30 & 100 & 14 & 0.3448 & 1.6822 & 1.6119 & 1.5914 \\
\hline 05Wi30 & 100 & 21 & 0.4044 & 1.7234 & 1.6757 & 1.638 \\
\hline $05 \mathrm{Wi} 30$ & 100 & 28 & 1615 & 1.7291 & 1.68 & 1.6529 \\
\hline 05Wi30 & 100 & 35 & 0.3827 & 1.7654 & 1.7103 & 1.6692 \\
\hline 05Wi30 & 100 & 42 & 0.3661 & 1.7835 & 1.7393 & 1.7028 \\
\hline 05Wi30 & 100 & 49 & 0.387 & 1.7476 & 1.6876 & 1.6524 \\
\hline 05Wi30 & 100 & 56 & 0.7741 & 1.625 & 1.4779 & 1.4065 \\
\hline $05 \mathrm{Wi} 30$ & 100 & 228 & 0.6614 & 1.7335 & 1.623 & 1.5555 \\
\hline 05Wi30 & 0 & 0 & 0.2773 & 1.7331 & 1.6785 & 1.6609 \\
\hline 05Wi30 & 200 & 3 & 0.3628 & 1.7709 & 1.705 & 1.6688 \\
\hline 05Wi30 & 200 & 7 & 0.3885 & 1.7237 & 1.7333 & 1.7237 \\
\hline 05Wi30 & 200 & 15 & 0.4631 & 1.7642 & 1.7328 & 1.7051 \\
\hline 05Wi30 & 200 & 21 & 0.373 & 1.7546 & 1.7116 & 1.6766 \\
\hline $05 \mathrm{Wi} 30$ & 200 & 29 & 3589 & 1.752 & 1.7083 & 1.6784 \\
\hline 05Wi30 & 200 & 35 & 4744 & 1.7217 & 1.6215 & 1.5713 \\
\hline & 200 & 44 & 1654 & 1.7474 & 1.6785 & 1.6479 \\
\hline & 200 & 198 & 366 & 1.6806 & 1.6802 & 1.6538 \\
\hline
\end{tabular}




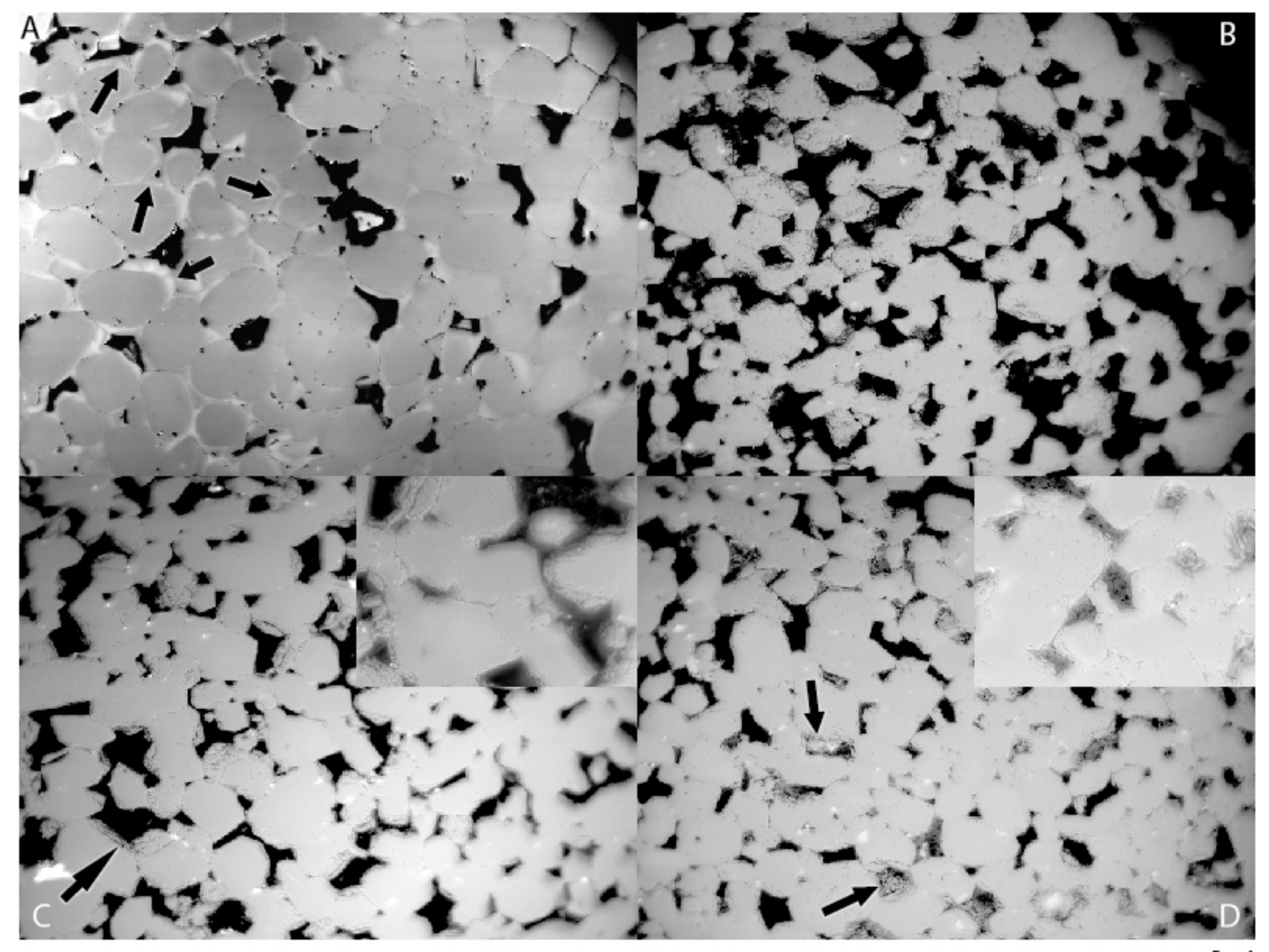




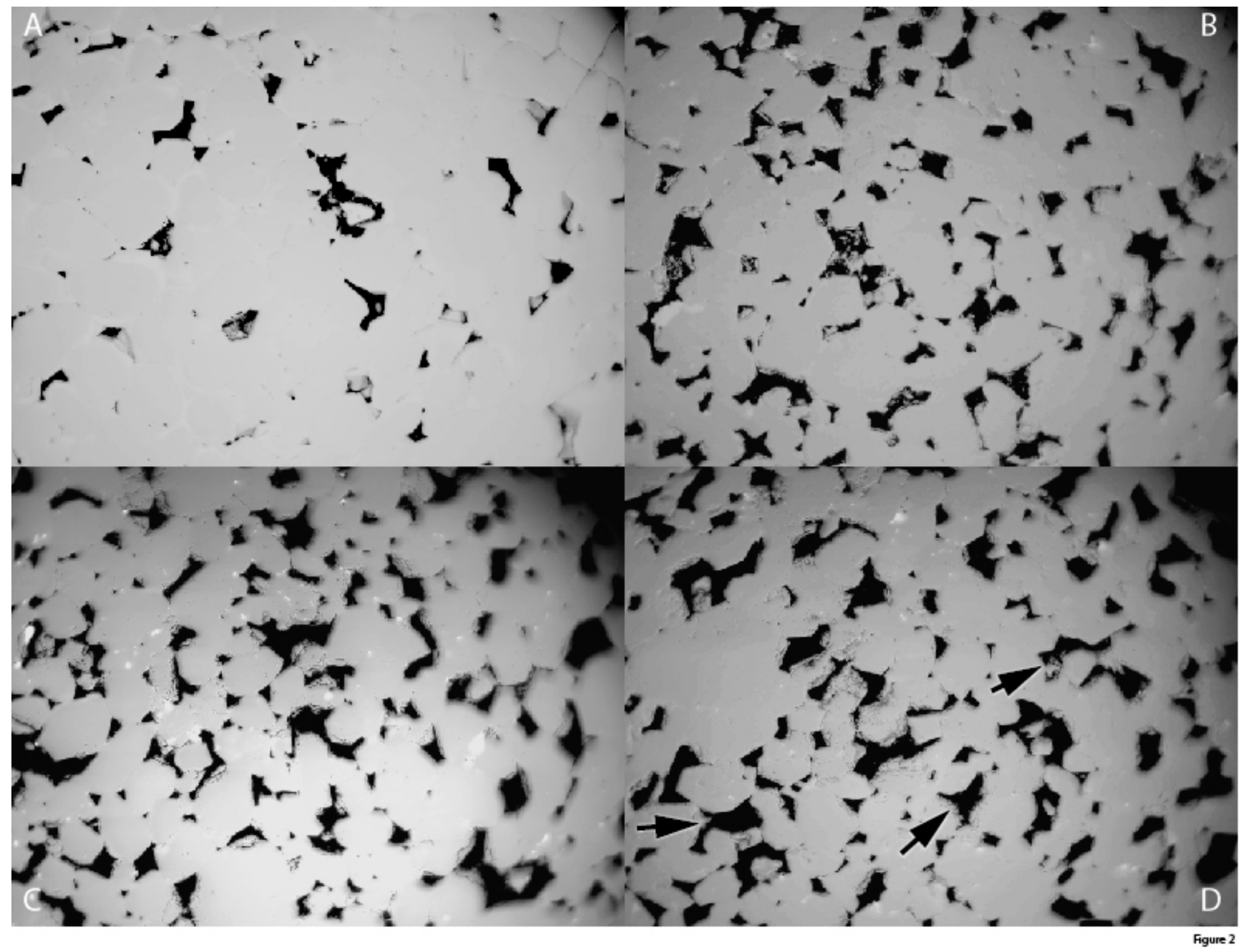




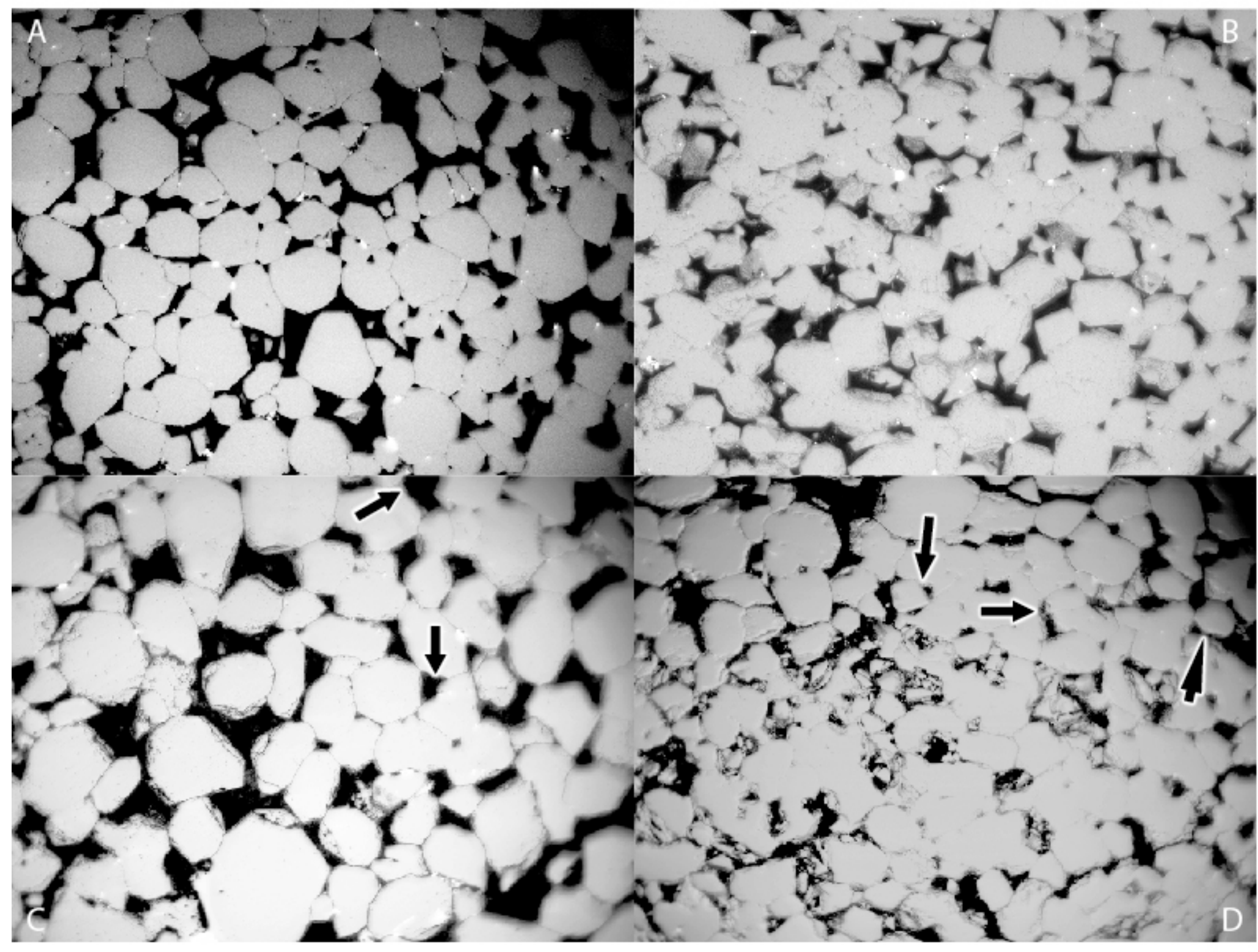




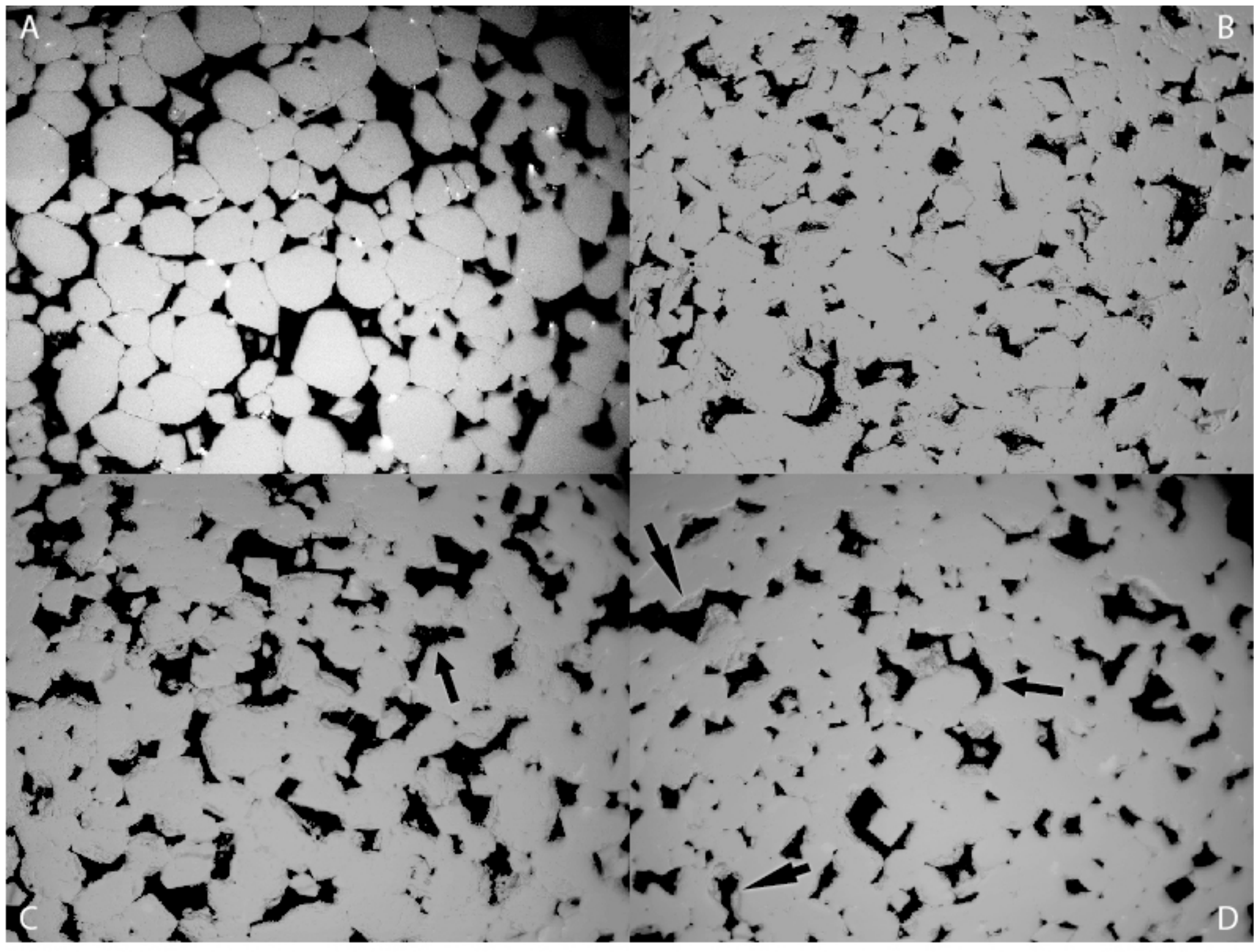




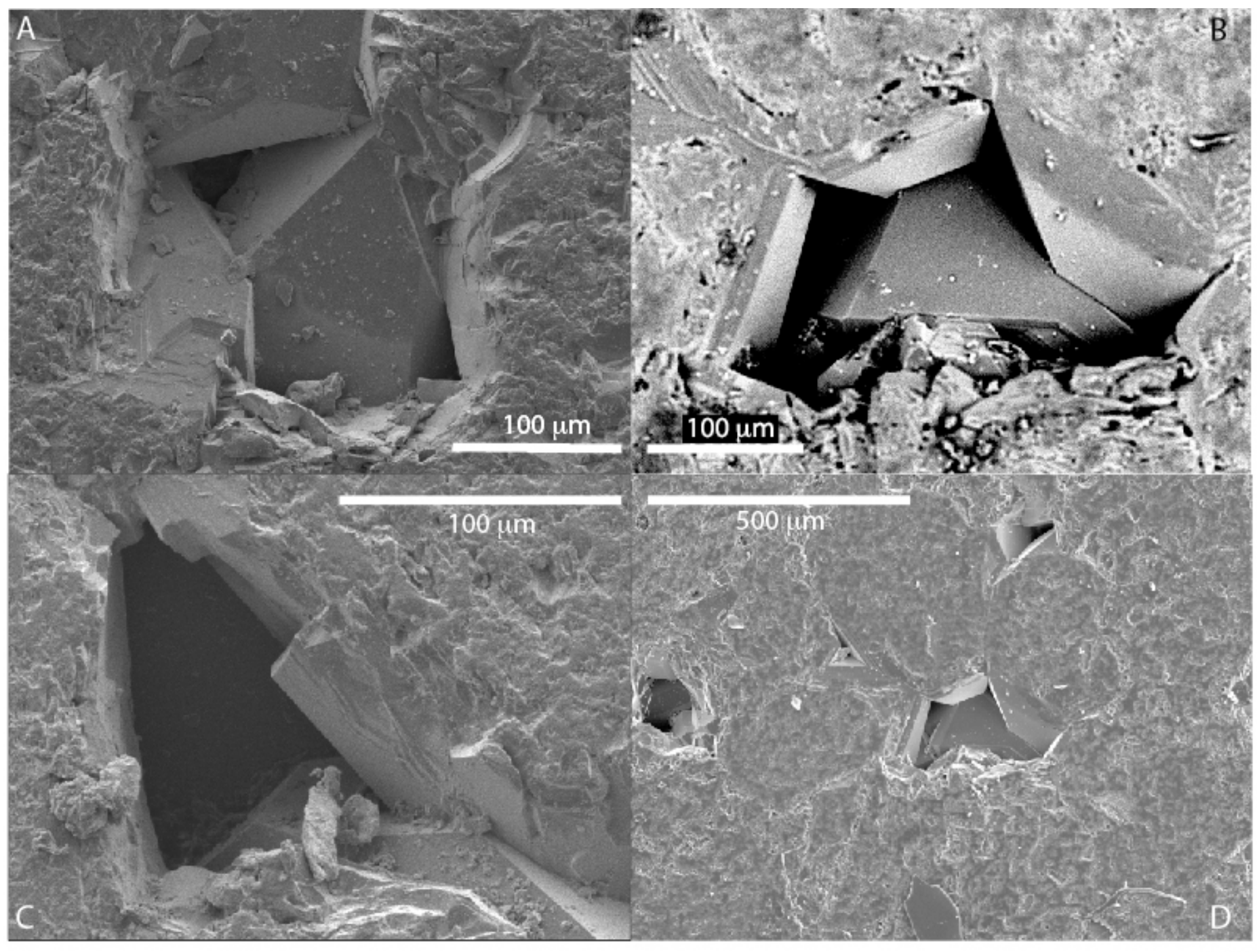

Figure 5 


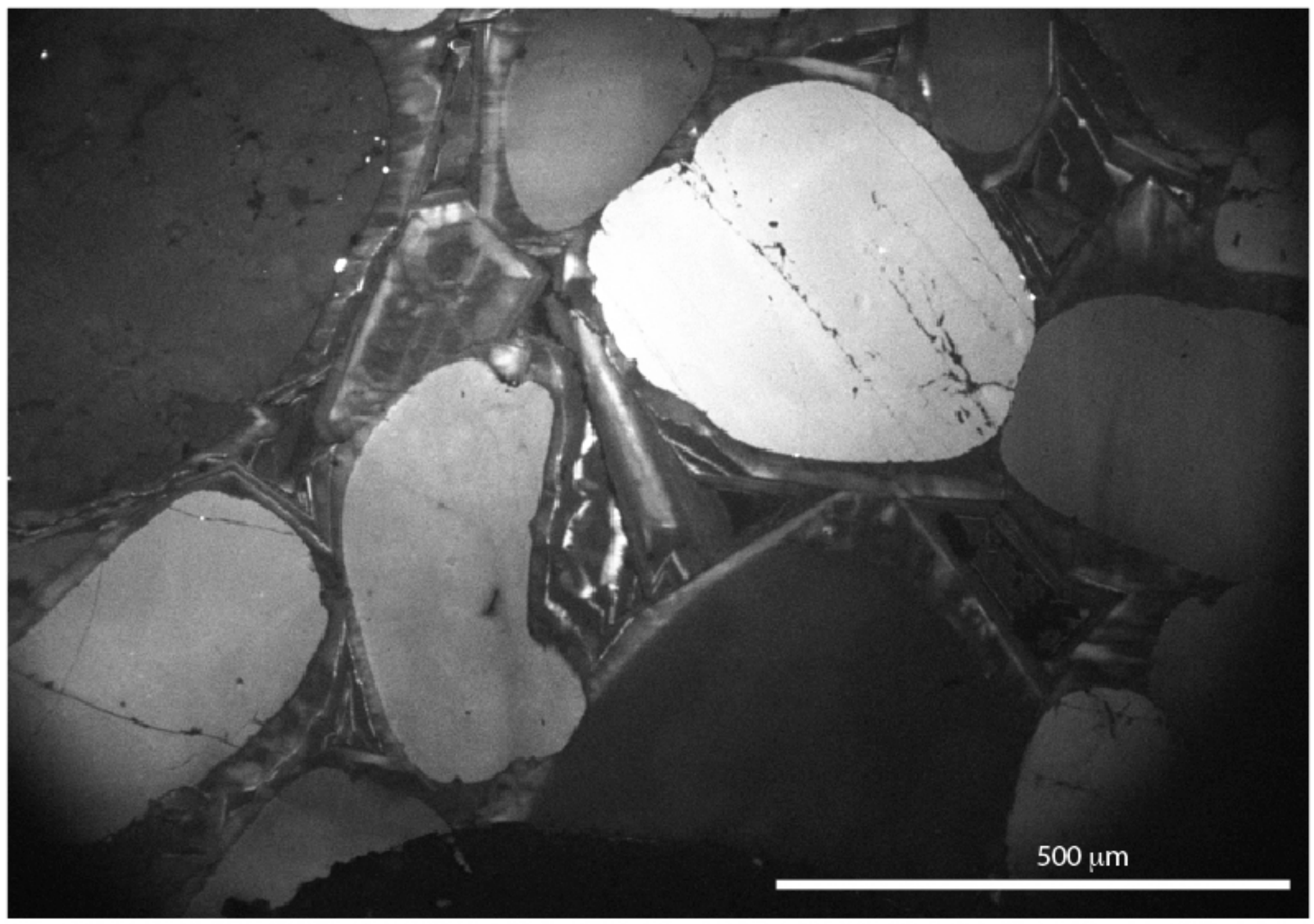

Figure 6 

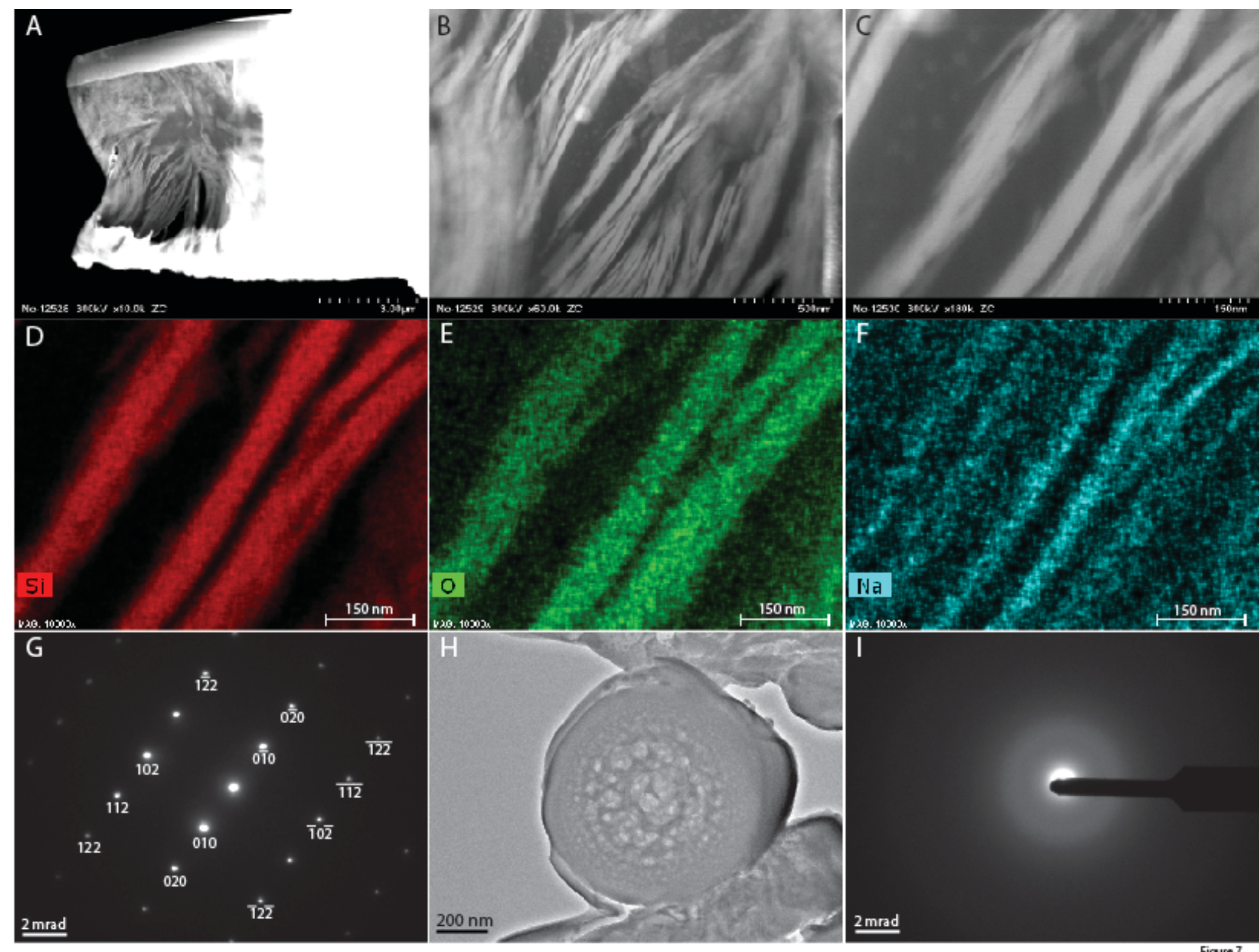

$150 \mathrm{~nm}$

Figure 7 


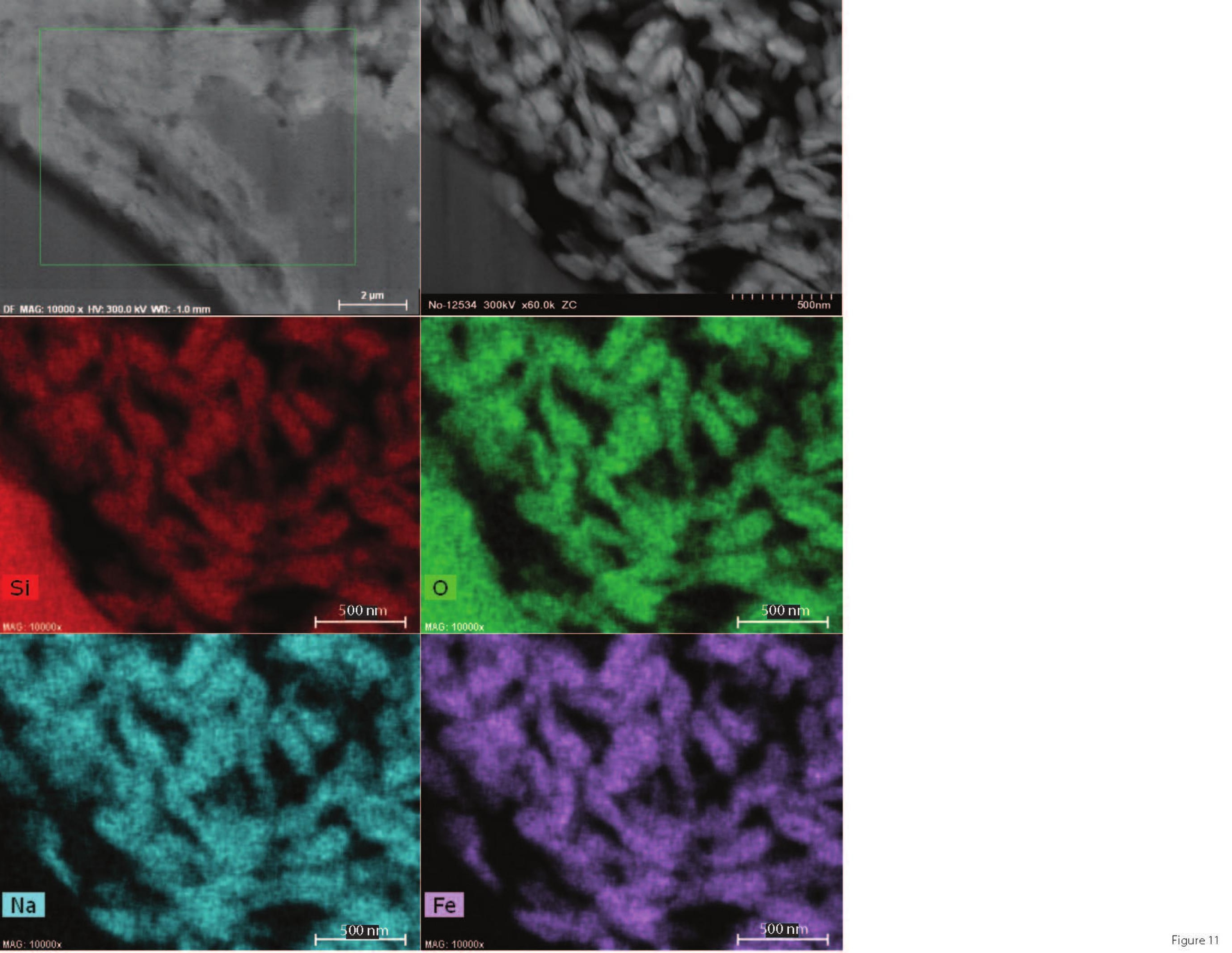




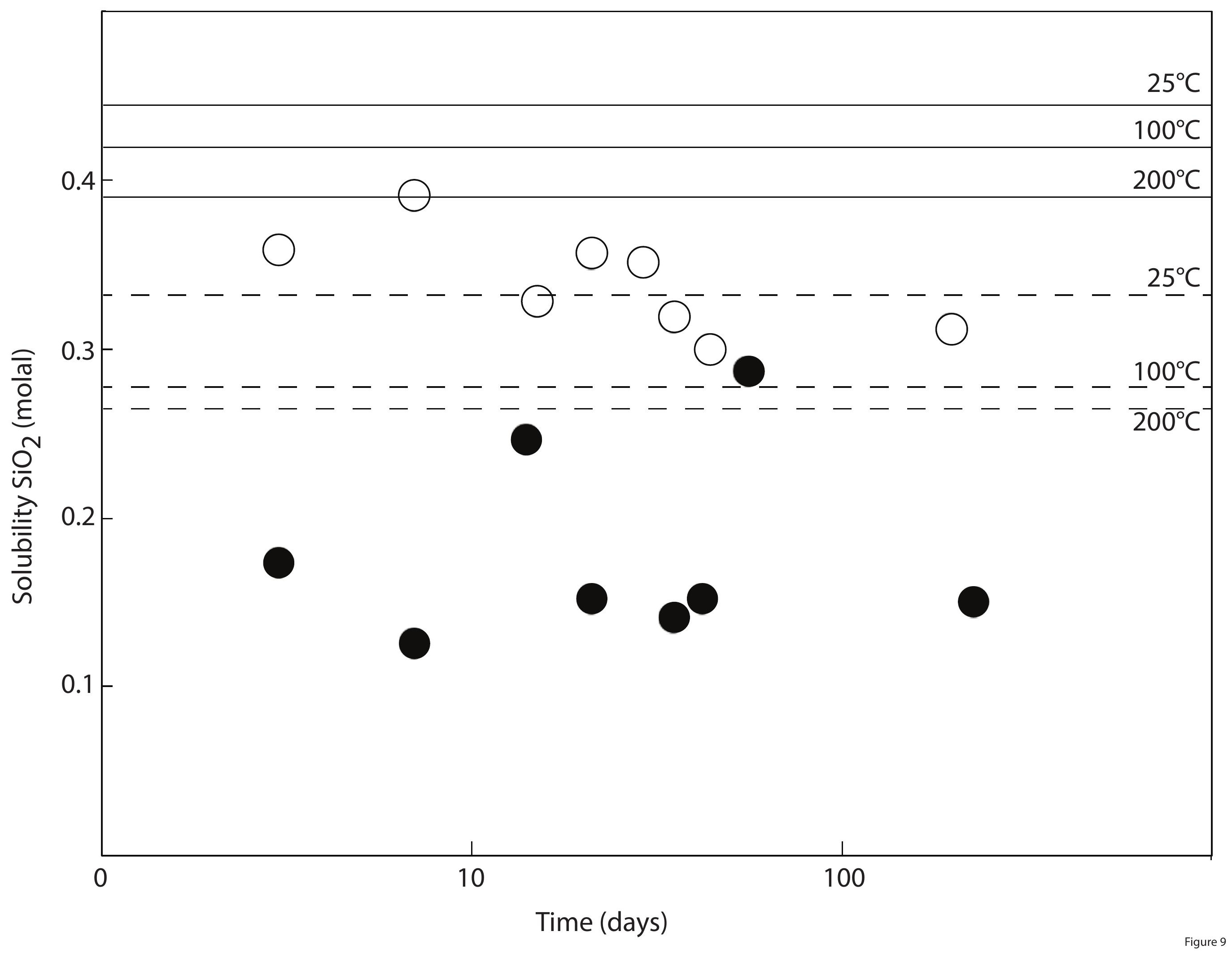




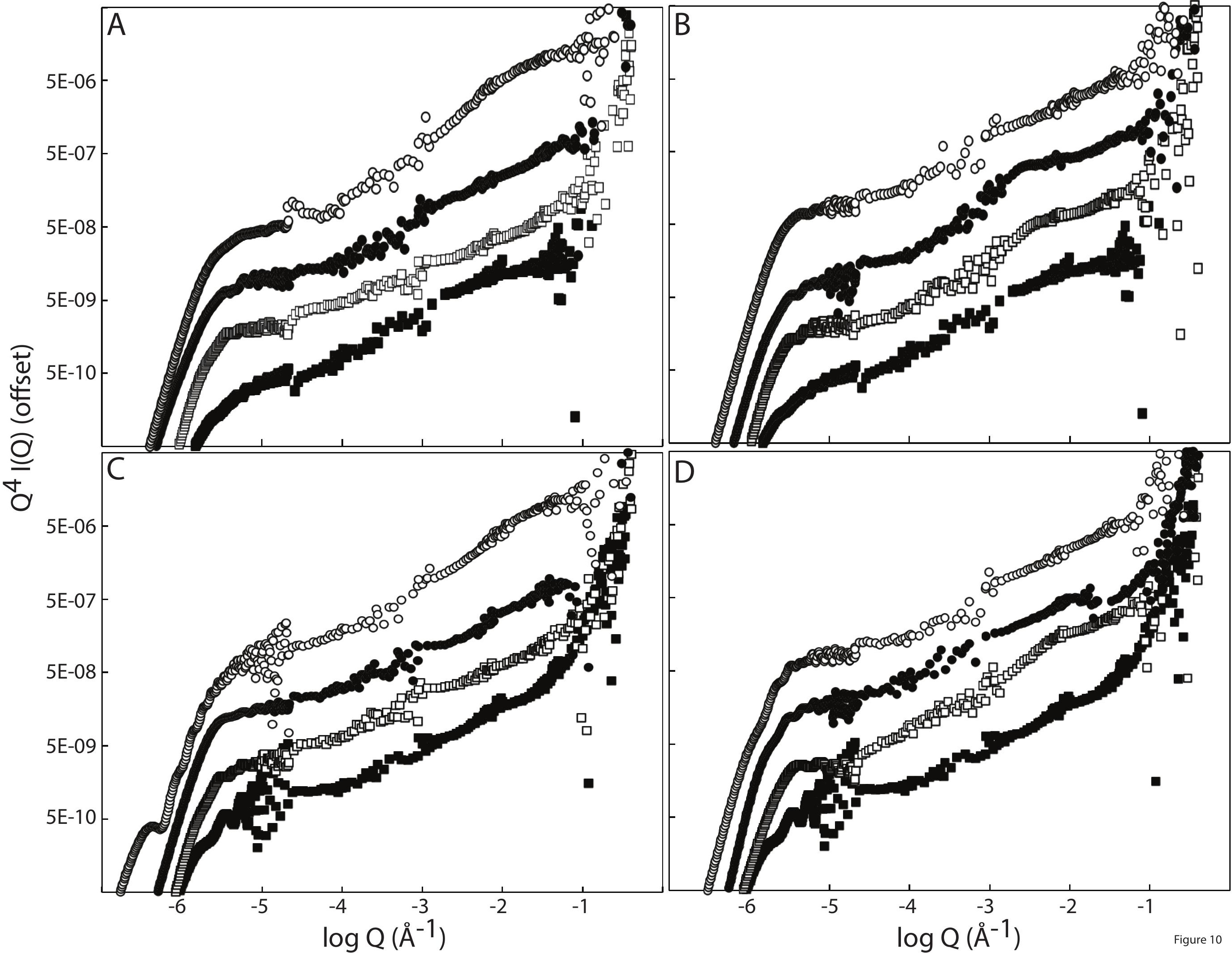




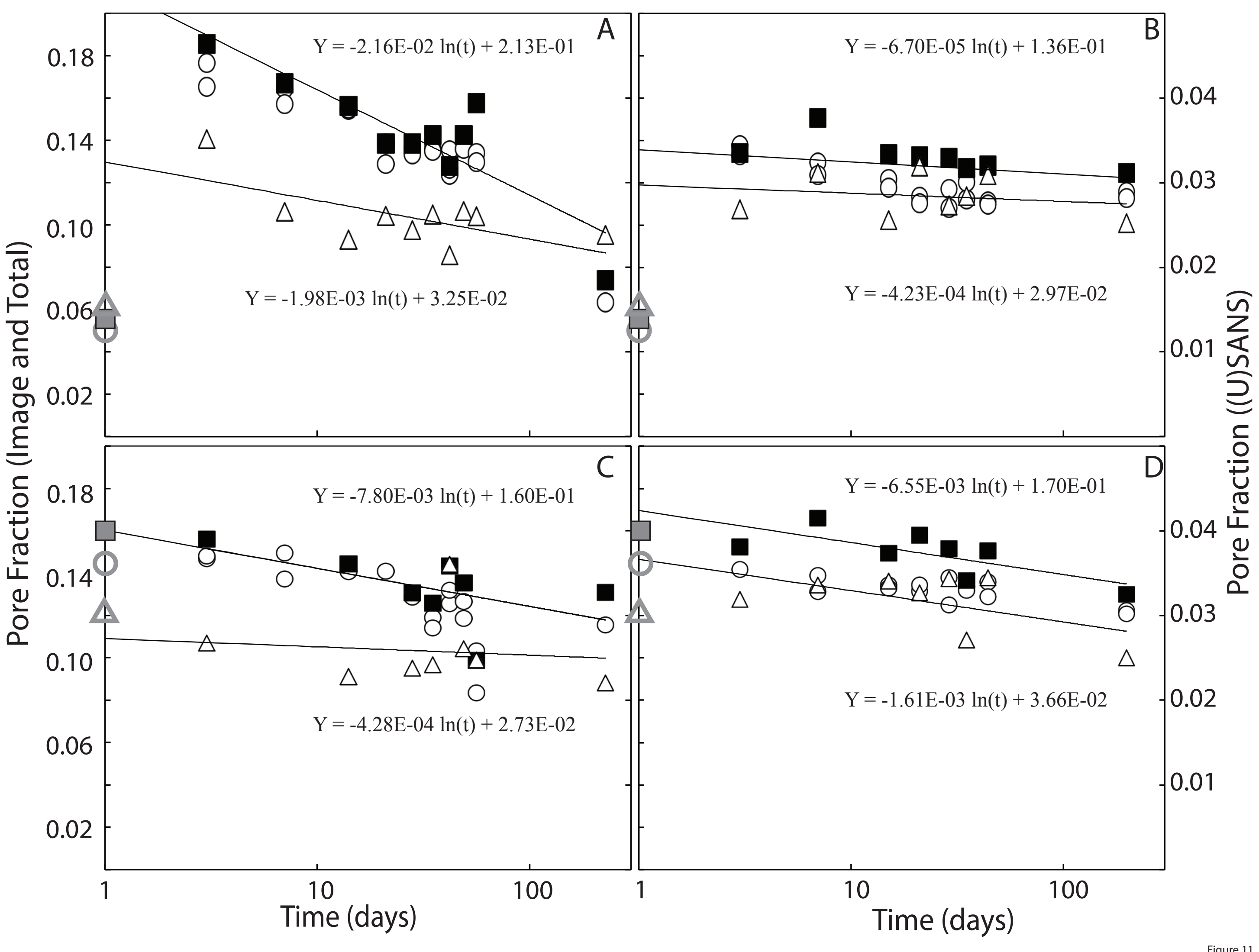




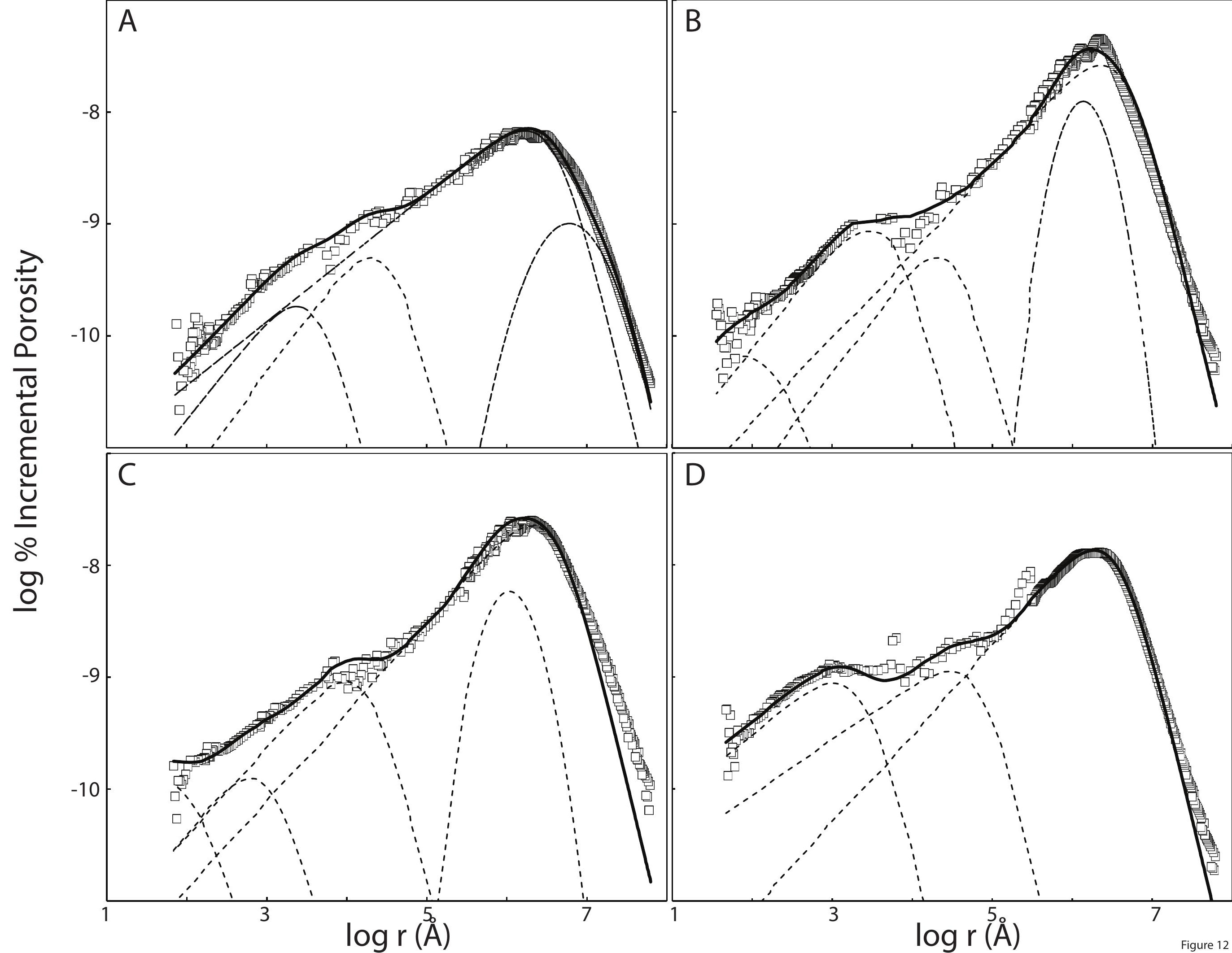




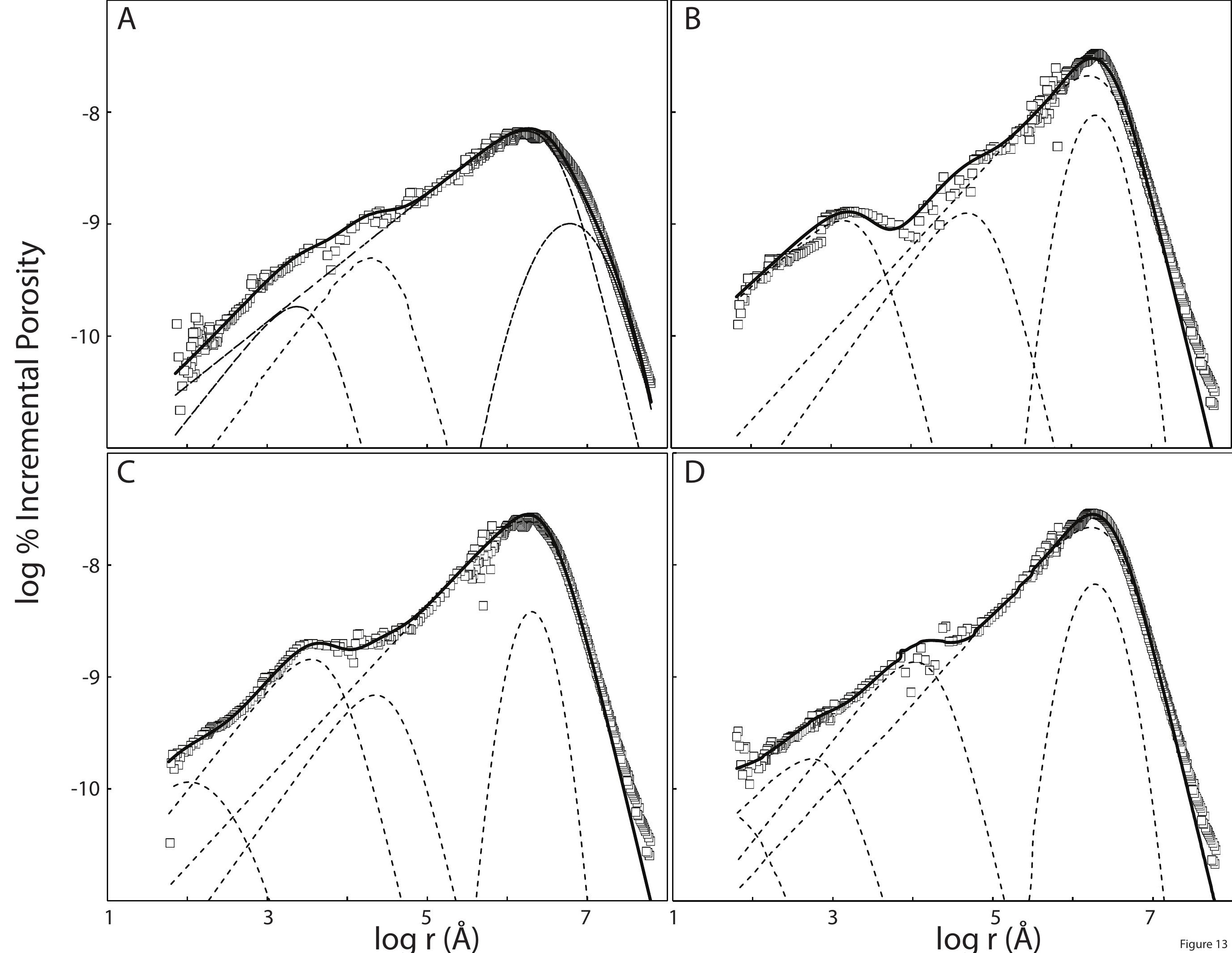




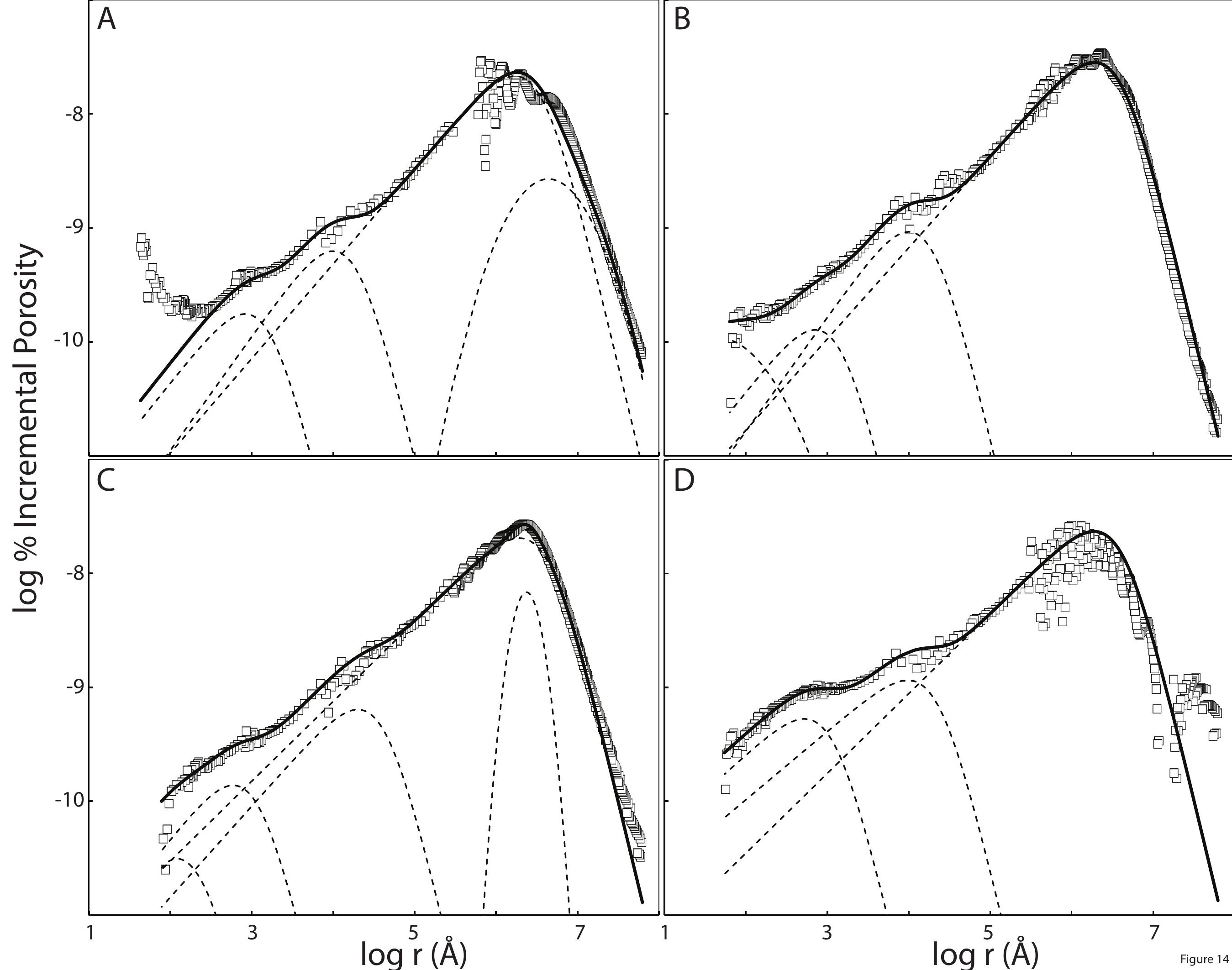




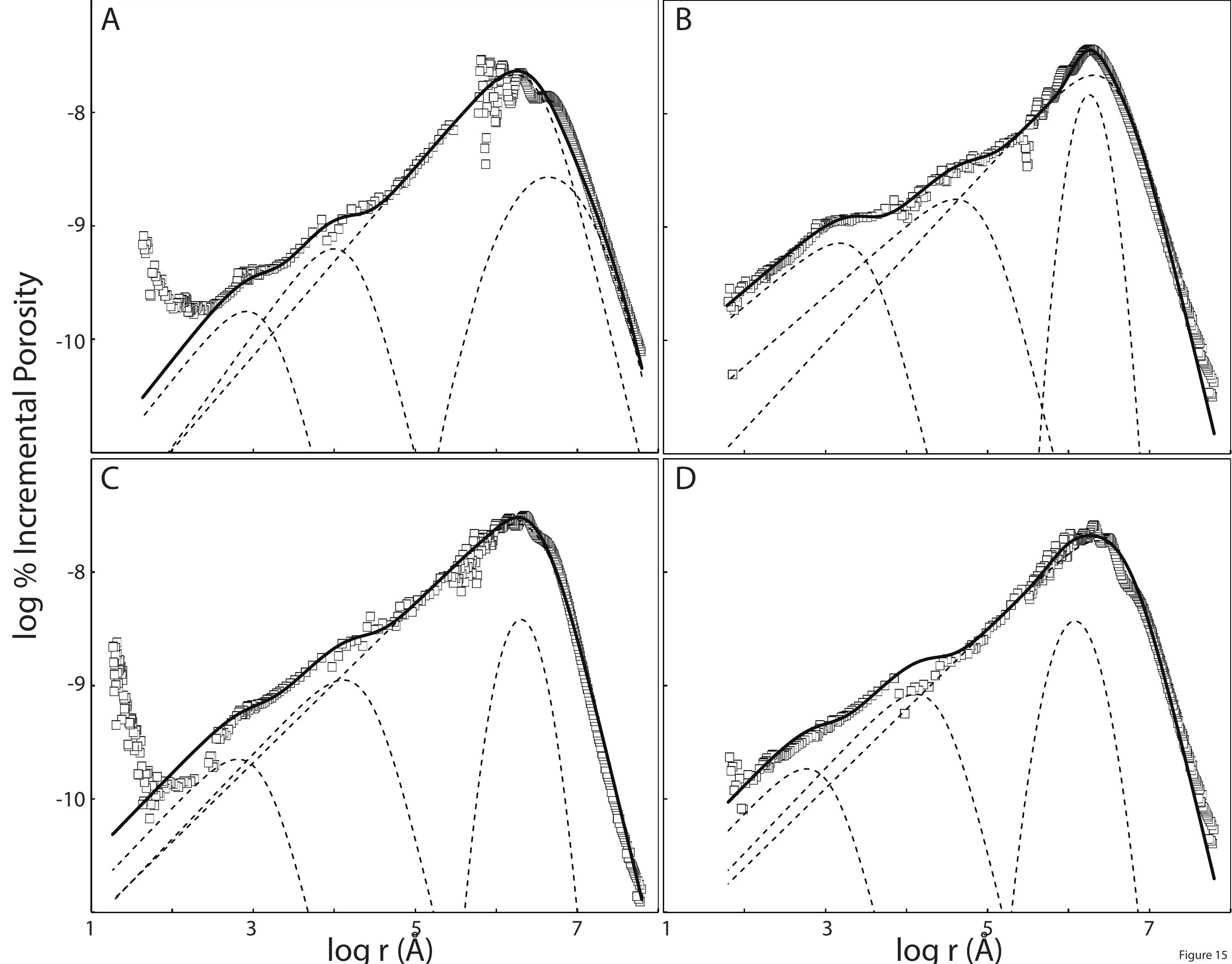




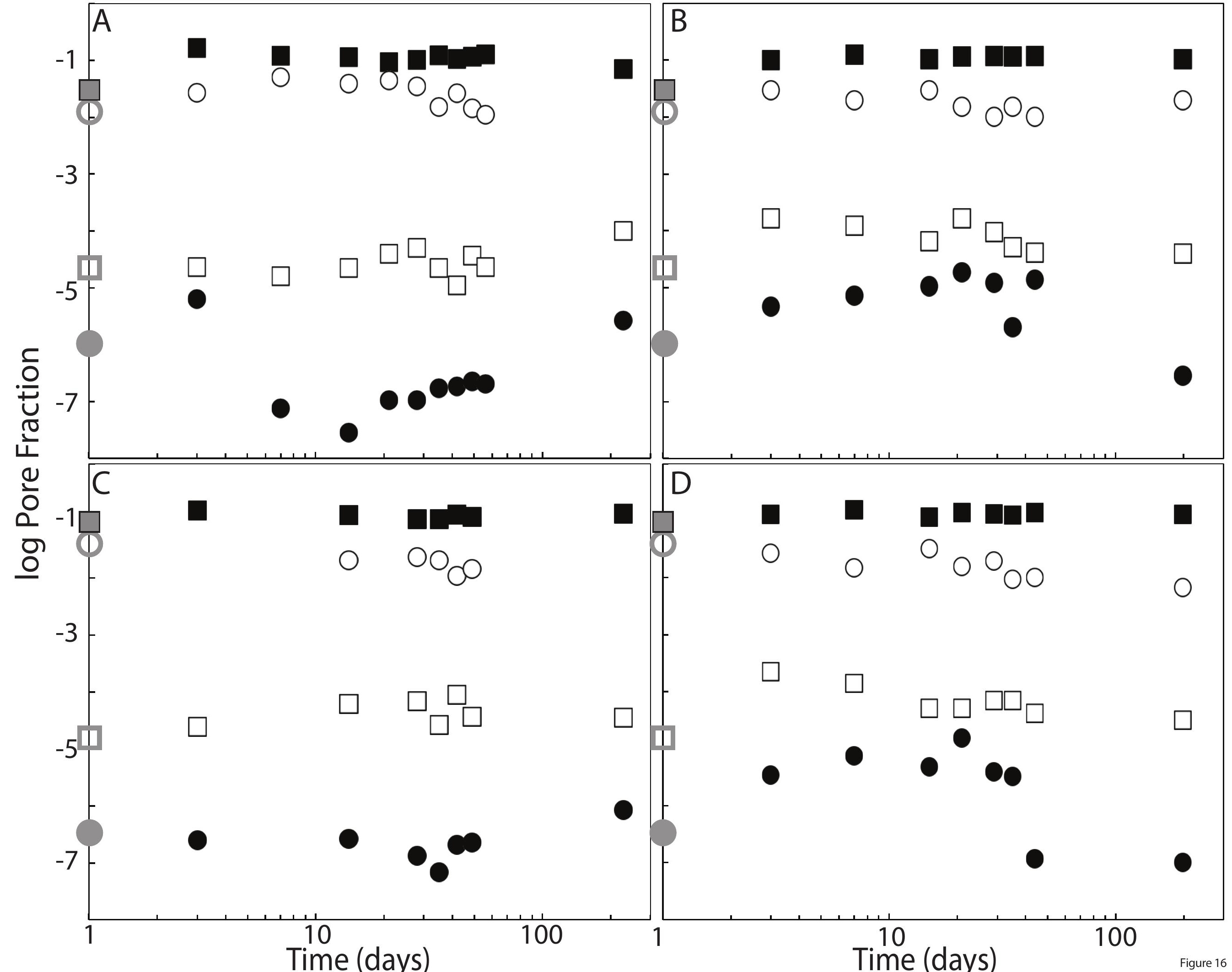




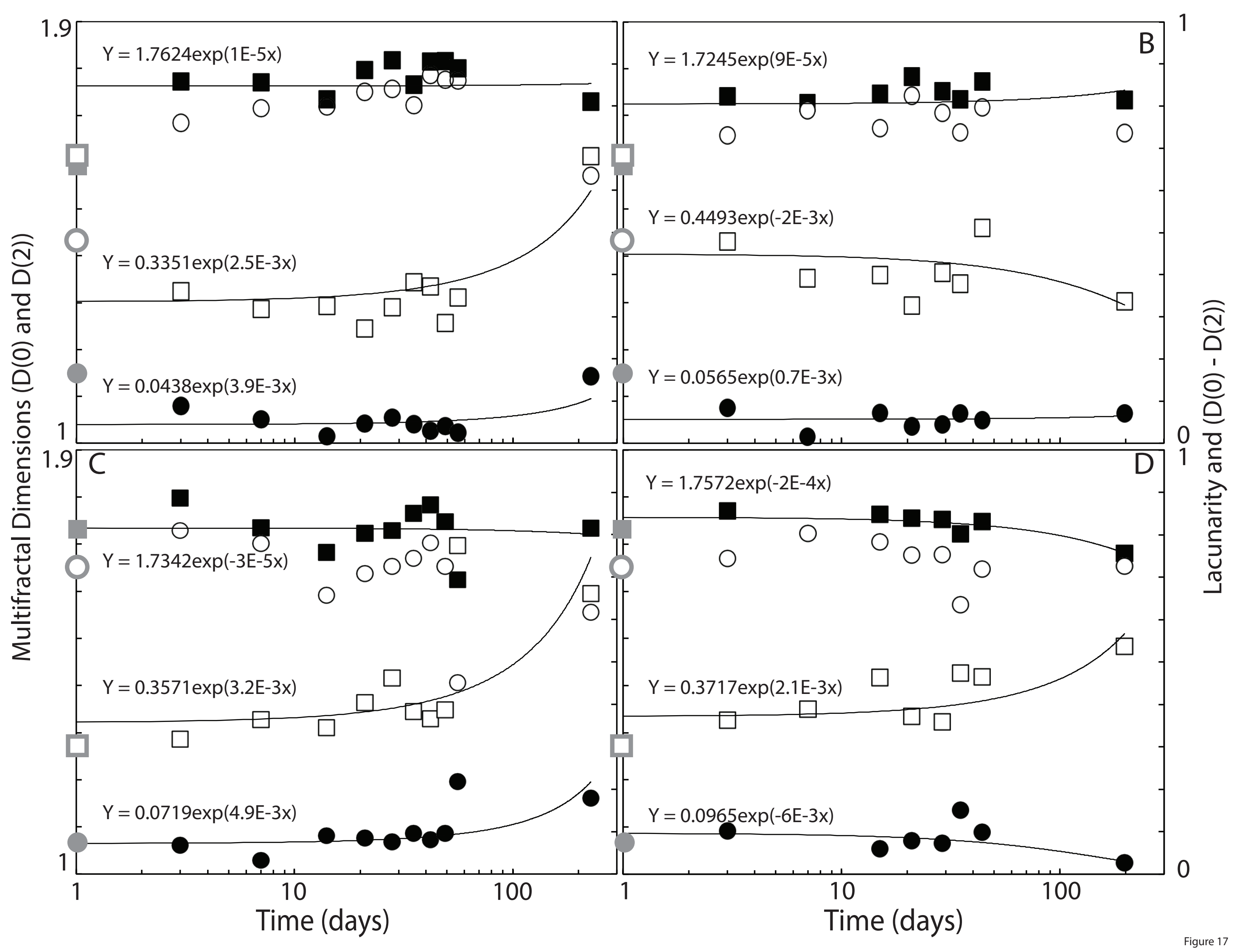

